\title{
Uma geometria tetradimensional euclidiana para os fenômenos relativistas: cinemática ${ }^{+*}$
}

Otávio Fossa de Almeida ${ }^{1}$

Secretaria de Estado de Educação do Rio de Janeiro

Rio de Janeiro - RJ

\section{Resumo}

O objetivo geral deste artigo é abrir uma nova linha de discussão no ensino da relatividade do movimento moderna, oferecendo uma abordagem geométrica euclidiana em quatro dimensões, que adota o tempo próprio como quarto eixo cartesiano. Essa iniciativa se deve ao fato de que são identificadas severas barreiras às tentativas, quando necessárias, de transposição dos fenômenos relativistas para a educação básica, principalmente porque a Teoria da Relatividade Especial (TRE) é muito abstrata e as Teorias do Espaço-tempo (TET) minkowskiana e da Relatividade Geral (TRG) exigem uma geometria não-euclidiana. Nesse contexto, essa nova geometria é focada, sobremaneira, na formação de professores, que são os artífices dessas transposições, e possui o objetivo especifico de explorar sua funcionalidade em descrever exclusivamente a cinemática relativista, sem definir uma grandeza para descrever a mudança do movimento, discutindo os problemas da dilatação do tempo, da composição de movimentos, da contração do comprimento e dos "paradoxos" dos gêmeos, da contração do espaço e do disco rígido girante. Esse objetivo específico é importante porque estes seis problemas não só são historicamente relevantes, como também servem como laboratório para testar a validade da nova geometria, que, apesar de equivalente à TRE e à TET, possui sua coesão interna.

\footnotetext{
${ }^{+}$A four-dimensional Euclidean geometry for relativistic phenomena: kinematics

* Recebido: 5 de outubro de 2020. Aceito: 12 de abril de 2021.

${ }^{1}$ E-mail: fossadealmeida@gmail.com
} 
Palavras-chave: Ensino de Física; Física Moderna e Contemporânea; Relatividade do Movimento Moderna; Geometria Euclidiana.

\begin{abstract}
The general goal of this article is to open a new line of discussion in teaching of modern relativity of motion, offering a four-dimensional Euclidean geometric approach which adopts proper time as the fourth Cartesian axis. This initiative is because many observe severe barriers to attempt to do transpositions of the relativistic phenomena to basic education when necessary, mainly because Special Theory of Relativity (STR) is very abstract, and Minkowskian Spacetime Theory (STT) and General Theory of Relativity (GTR) requires a non-Euclidean geometry. In this context, this new geometry is mainly focused on the training of teachers, who are the creators of these transpositions, and has the specific goal of exploring its functionality in describing exclusively the relativistic kinematics, without defining a quantity to describe the change of movement, discussing the problems of time dilation, composition of movements, length contraction and the "paradoxes" of twins, contraction of space, and rigidly rotating disk. This specific goal is important because these six problems are not only historically relevant, but also serve as a laboratory to test the validity of this new geometry, which, although equivalent to STR and STT, has its internal cohesion.
\end{abstract}

Keywords: Physics Education; Modern and Contemporary Physics; Modern Relativity of Motion; Euclidean Geometry.

\title{
I. Introdução
}

O ensino da Física Moderna e Contemporânea (FMC) para a educação básica tornouse, nas últimas décadas, uma área de pesquisa razoavelmente popular no Brasil; e um dos argumentos pioneiros para justificá-lo foi que a Física escolar estava defasada no tempo, pois os tópicos estudados se concentravam principalmente naqueles desenvolvidos entre os anos 1600 e 1850 (TERRAZZAN, 1992). Ostermann e Moreira (2000), por exemplo, esforçaramse em levantar justificativas em prol da inclusão de assuntos ligados à FMC nas escolas, como: ajudar os estudantes a reconhecer a Física como um empreendimento humano, atrai-los para a carreira científica, protege-los das pseudociências e do charlatanismo, discutir sobre suas muitas consequências tecnológicas, etc. Entretanto, por mais que essa etapa de levantamento de justificativas esteja superada em vários "países desenvolvidos" 
(OSTERMANN; RICCI, 2002) e por mais que já exista um certo consenso sobre sua importância na literatura brasileira (RODRIGUES; SAUERWEIN; SAUERWEIN, 2014), ainda é possível encontrar muitos argumentos falaciosos referentes ao ensino da FMC; sobretudo no que tange aos fenômenos relativistas, cujo interesse foi potencializado nos últimos anos graças ao aniversário de fundação da Relatividade Geral (SAMPAIO; OLIVEIRA; SIQUEIRA, 2019), ao centenário das observações do eclipse de Sobral (SALINAS, 2019), à descoberta das ondas gravitacionais (LIGO SCIENTIFIC COLLABORATION; VIRGO COLLABORATION, 2016) e à primeira imagem de um buraco negro (EVENT HORIZON TELESCOPE COLLABORATION, 2019).

É claro que a retórica é importante em qualquer comunicação, mas ela não deve perder-se em excessos; e é possível identificar uma série de falácias comuns para justificar o ensino da FMC, como a falácia do "apelo ao assunto cativante", em que os alunos da educação básica se sentiriam, supostamente, mais motivados a estudar Física se esses assuntos fossem explorados no currículo. Talvez, aqueles que defendem tal argumento sejam motivados por suas próprias paixões, mas isso não significa que todos tenham os mesmos gostos, os mesmos interesses ou sejam obrigados a partilhá-los. Infelizmente, o tempo em sala de aula é limitado, o acúmulo de conhecimento é gigantesco e o apelo a interesses pontuais ou ao simples "amor pelo conhecimento" não é suficiente para escolher o quê ensinar. Outra falácia comum é o "apelo ao assunto recorrente em sala de aula", que prega que os alunos fazem, a todo momento, comentários e perguntas sobre tópicos da FMC. Isso é um exagero. $\mathrm{Na}$ verdade, são pouquíssimos aqueles que o fazem, e de forma esporádica. Muitas vezes, esses estudantes são classificados como nerds e entram em contato com esses assuntos a partir de documentários de TV, filmes e séries de ficção científica ou em games, o que dá margem a outra falácia notável: o "apelo ao cotidiano do aluno". Considerar que a FMC faz parte do cotidiano é uma falácia preocupante, pois quase não existem, ainda, aplicações reais e acessíveis no dia a dia. No caso específico dos fenômenos relativistas, o leitor irá imediatamente pensar em tecnologias como o GPS, mas essa não só é a única aplicação disponível no cotidiano, como também é uma "caixa preta", uma tecnologia de meandros inacessíveis aos estudantes. Mais um argumento falacioso é o "apelo à importância histórica", isto é, que o caminho heurístico-histórico deve ser o melhor caminho pedagógico. Nesse caso, é possível identificar vários argumentos falhos, mas o mais evidente no que tange à FMC é que os alunos devem compreender a ruptura de paradigmas, a "revolução científica", ocorrida no começo do século XX. É ingenuidade acreditar que os alunos da educação básica conseguirão compreender o profundo significado dessa ruptura, pois eles não possuem conhecimentos prévios adequados e suficientes sobre os fenômenos clássicos para se sentirem consternados com os fenômenos modernos e contemporâneos. Os estudantes não possuem até mesmo uma "visão aristotélica" de mundo (REZENDE; BARROS, 2001), logo, a verdadeira ruptura que ocorre em sala de aula é entre o senso comum, um emaranhado de concepções e modelos mentais em voga na sociedade, e a estrutura formal do saber escolar. 
Existem muitas outras falácias que poderiam ser discutidas aqui, mas isso desviaria o foco deste artigo, pois seu objetivo não é argumentar contra o ensino da FMC. É importante dar-lhe uma justificativa real e profunda, algo indiscutível até entre os detratores, e, talvez, os melhores argumentos para embasá-lo, especialmente em relação aos fenômenos relativistas, são: i) ele é importante na formação de professores, tanto porque é um tema relevante da Física, quanto porque pode ser necessário em sua vida profissional, e ii) funciona como preparação para uma possível demanda da sociedade, pois é fundamental existir uma boa literatura prévia discutindo as diversas técnicas de ensino, seus prós e contras, as dificuldades apresentadas pelos estudantes na aprendizagem, etc. Agora, o conteúdo de relatividade moderna ensinado nas licenciaturas é suficiente para formar professores capazes de lidar com esse assunto em sala de aula quando for necessário? Sampaio, Oliveira e Siqueira (2019), por exemplo, fazem uma breve análise a respeito do que pensam os professores da educação básica sobre o ensino de tópicos de relatividade nessa etapa de formação, concluindo, a partir da revisão da literatura, que a maioria dos entrevistados pelas fontes revisadas confirmam que esse ensino é importante. Entretanto, como argumentos contrários, são citados: a falta de tempo em sala de aula para discutir o assunto, a baixa compreensão da maioria dos alunos e, o que chamou mais atenção, a falta de preparação dos professores para lidar com o tema.

Por mais que o campo amostral da pesquisa revisada por Sampaio, Oliveira e Siqueira (2019) sobre a falta de preparação dos professores seja pequeno, apenas 9 entrevistados, a experiência pessoal deste presente autor, que é professor da educação básica, aponta que existem dificuldades não desprezíveis em seu próprio trabalho e no dos colegas. A mesma percepção ocorre em relação às tentativas de transposição propostas no âmbito dos mestrados profissionais ou naquelas apresentadas no Simpósio Nacional de Ensino de Física (SNEF). Se as discussões anteriores foram justificativas "acadêmicas" para este presente trabalho, as dificuldades apontadas acima são as justificativas práticas para o desenvolvimento da abordagem que será discutida aqui. Então, qual poderia ser a causa dessas dificuldades? Talvez, a resposta mais imediata seja que as abordagens usuais para explicar os fenômenos relativistas são muito abstratas. Ostermann e Moreira (2000) rebatem que essa característica seria um empecilho para o ensino da FMC, pois a Física Clássica também é abstrata, mas, nesse ponto, há algo de diferente: A Relatividade Clássica é abstrata e anti-intuitiva, mas não é difícil convencer os estudantes de sua validade a partir de argumentos empíricos simples e cotidianos. Já a abordagem de princípios da Teoria da Relatividade Especial (TRE) de Einstein (1905), não só trata de experimentos de reprodução quase impossível em contexto educacional, como requer um grande poder de abstração para compreender seus experimentos mentais. Isso não parece óbvio quando se trata de fenômenos imediatos como a contração espacial ou a dilatação temporal, mas torna-se dramático na solução dos paradoxos aparentes que decorrem deles.

Em relação à abordagem geométrica inaugurada pela Teoria do Espaço-Tempo (TET) de Minkowski (1908), ela será tratada, aqui, por motivos históricos, como uma 
abordagem diferente dos princípios da TRE, mesmo que sejam complementares. O espaçotempo minkowskiano possui a vantagem de permitir a visualização dos fenômenos relativistas a partir de diagramas, o que facilitaria a discussão se ela não fosse uma geometria hiperbólica; e Einstein e Laub (1908), inicialmente, consideraram que essa complicação matemática era supérflua frente à "forma elementar" da TRE. O leitor pode perguntar-se, mas qual o problema em ensinar geometrias não-euclidianas aos alunos de graduação? Em princípio, nenhuma. É importante que eles tenham essa formação, mas o ideal não se coaduna com o real nas licenciaturas, além de ser um conteúdo de difícil transposição para a educação básica. Por último, em relação à Teoria da Relatividade Geral (TRG), que unifica e generaliza as duas abordagens anteriores, não há muito o que argumentar, pois ela é um tema próprio da pósgraduação. Nesse panorama, o que se vê nas tentativas de transposição se resume a i) discussões puramente históricas e conceituais e a ii) discussões algébricas que, usando apenas os princípios da TRE, tratam superficialmente os fenômenos da dilatação temporal, da contração do comprimento e, talvez, da composição de velocidades.

Não há demérito nesses esforços, pois, dependendo da realidade didática de uma turma, é válido fazer até mesmo a apresentação de documentários sob a orientação do professor, mas incomoda a percepção de que é impossível ir além dessas tentativas rasteiras; e isso sem nem mesmo vislumbrar o nível da TRG. Com isso, este presente trabalho possui o objetivo geral de abrir uma nova linha de discussão no ensino da relatividade do movimento moderna, divulgando uma geometria euclidiana em quatro dimensões que adota o tempo próprio como quarto eixo cartesiano. Essa "nova" abordagem parece ter potencial como ferramenta educacional e vale a pena trazê-la à luz e oferecê-la à apreciação dos colegas brasileiros, mesmo que ainda esteja em estado embrionário quando comparada às abordagens canônicas da TRE e da TET, bem conhecidas. Por esse motivo, o objetivo específico deste artigo é explorar sua funcionalidade em descrever a cinemática relativista, discutindo os fenômenos da dilatação temporal, da composição de movimentos e da contração do comprimento e os paradoxos aparentes dos gêmeos, da contração do espaço e do disco rígido girante. Esse objetivo específico é importante porque, apesar da nova geometria apresentar uma mudança radical na estrutura métrica e uma alteração profunda na compreensão do tempo, ela precisa se demonstrar tão eficaz, em termos de resolução de problemas, quanto as abordagens canônicas. Ser eficaz é o mínimo que se espera para oferecê-la aos colegas e fomentar o debate.

\section{Uma breve apresentação histórico-conceitual}

É natural que uma nova linha de pesquisa seja apresentada com cautela e, para entender o que se pretende fazer aqui, é importante recorrer a duas das discussões mais fundamentais feitas por Einstein (1905) em seu artigo fundador da TRE: a necessidade de que as medidas de um evento sejam feitas imediatamente em sua vizinhança e que cada relógio 
possui seu próprio tempo, que não é necessariamente um tempo comum. Essas constatações permitiram-lhe tecer considerações sobre os conceitos de sincronização e simultaneidade, mas, ao analisar o movimento de um ponto material em relação a dois sistemas de coordenadas espaciais em movimento relativo, Einstein (1905) relacionou diretamente essas coordenadas ao tempo medido por relógios fixos em cada um deles. Essa relação parece ser bastante espontânea e Minkowski (1908), ao criar a abordagem geométrica da TET, definiu seu vetor espaço-tempo considerando esse tempo como um eixo ortogonal aos eixos cartesianos do espaço. Porém, essa associação é indelével ou é oriunda apenas de um consenso entre os cientistas? Se for uma convenção, quais suas origens?

Partindo do pressuposto que a ciência não é dogmática, essa convenção possui motivações distintas nas duas abordagens. No primeiro caso, a grande preocupação de Einstein (1905) era a origem cinemática das transformações do Eletromagnetismo e a sincronização de relógios; e essa última fê-lo conceber que o tempo deve ser medido por relógios em repouso. Já a preocupação de Minkowski (1908) foi mais formal, em consonância com o pensamento defendido, na época, pelos matemáticos da Universidade de Göttingen; e levou em consideração não só os postulados propostos por Einstein (1905), como também o trabalho de Poincaré (1906), que foi o primeiro a identificar a estrutura de invariantes da teoria lorentziana. Nesse contexto, a base da abordagem da TET é a métrica:

$$
c^{2} \mathrm{~d} \tau^{2}=c^{2} \mathrm{~d} t^{2}-\mathrm{d} x^{2}-\mathrm{d} y^{2}-\mathrm{d} z^{2}
$$

com $\tau$ sendo nomeado de tempo próprio. Da eq. (1), considerando $\tau$ um invariante, é possível extrair a regra de transformação entre os referenciais inerciais, mas a estrutura hiperbólica da geometria causou um estranhamento inicial, fazendo com que Minkowski (1908) definisse seu vetor espaço-tempo, em notação modernizada, como $(x ; y ; z ; i t)$, com $i=\sqrt{-1}$. Também, a estrutura geométrica exigiu uma axiomatização muito mais elaborada que os dois postulados propostos por Einstein (1905), o que deve ter motivado a crítica de Einstein e Laub (1908). Todavia, apesar dessas duas abordagens possuírem motivações distintas, elas fundamentam-se na mesma concepção espontânea corrente no início do século XX: a concepção de que o tempo está intimamente ligado ao lugar no espaço. Galison (2004), por exemplo, faz um profundo estudo externalista a respeito da influência, no desenvolvimento da relatividade moderna, da problemática sobre a medida do tempo, identificando-a num período pósRevolução Industrial em que o fluxo de pessoas, informações, matérias-primas e mercadorias tornou-se mais intenso e mais rápido; em que foram criadas as ferrovias, a telegrafia e a navegação movida a motores à vapor; e em que se debateu o conceito de hora local, o tempo associado a uma localidade fixa sobre a superfície da Terra. Graças a esse debate, foram definidos os fusos horários e o padrão internacional de tempo baseado no meridiano de Greenwich.

A concepção de que o tempo está ligado ao espaço parece estar arraigada na comunidade científica até os dias atuais, mas não sem contestação. Newburgh e Phipps Jr. 
(1969) foram os primeiros a propor uma mudança radical na estrutura métrica, provavelmente após a constatação de que a eq. (1) podia ser reescrita como:

$$
c^{2} \mathrm{dt}^{2}=c^{2} \mathrm{~d} \tau^{2}+\mathrm{d} x^{2}+\mathrm{d} y^{2}+\mathrm{d} z^{2}
$$

que tem o conveniente aspecto de uma métrica euclidiana, mas perde a propriedade de levar imediatamente às transformações entre os referenciais inerciais. Em princípio, isso não é um problema, pois as transformações e os invariantes podem ser recuperados de outra maneira, como será demonstrado neste artigo. A eq. (2) permitiu que os autores propusessem o chamado "diagrama espaço-tempo próprio" (NEWBURGH; PHIPPS JR., 1969), cuja interpretação física ficou pouco clara, mesmo que eles tenham tentado fundamentá-la em argumentos termodinâmicos (NEWBURGH; PHIPPS JR., 1970). Para esses autores, como $\tau$ estaria associado a uma característica térmica intrínseca do corpo, a representação do movimento de vários corpos em um mesmo diagrama não faria sentido e, dessa maneira, cada móvel deveria ser representado separadamente, formando uma geometria privativa ou "solipsística". Duas décadas mais tarde, Montanus (1991) retomou essa abordagem de maneira, ao que parece, independente sob o nome de "espaço-tempo absoluto euclidiano" e debruçou-se sobre ela por anos, divulgando-a consideravelmente. É fundamental esclarecer, que o adjetivo "absoluto" empregado não se relaciona às ideias newtonianas de espaço e de tempo, mas significa apenas a existência de um "referencial preferencial" (MONTANUS, 1999), inercial, para a descrição dos fenômenos físicos. Um avanço relevante de Montanus foi livrar-se da restrição de uma geometria privativa, onde cada corpo só podia ser representado individualmente, adotando uma geometria coletiva, em que vários movimentos eram descritos em um mesmo diagrama. Isso, é claro, não apaga o fato de que cada relógio tenha uma alteração particular na medida do tempo conforme sua velocidade, mas permite visualizar como essas alterações se relacionam.

Nos últimos anos, van Linden (2018) fez, em seu sítio da internet, um bom recenseamento das principais obras em língua inglesa sobre a nova abordagem, enquanto Jegat (2014) parece tê-la redescoberto de forma independente e tentado divulgá-la para a comunidade francesa. Já em relação ao ensino dessa geometria euclidiana tetradimensional, a proposta de "transposição didática" criada por Almeida (2013) provavelmente foi a primeira e a única de seu gênero e foi direcionada aos seus alunos do Ensino Médio. Segundo esse autor, os elementos que motivaram seu uso foram i) a possibilidade de uma representação visual usando as propriedades da geometria euclidiana e ii) a analogia, em duas dimensões, entre o "mapa do espaço-tempo" (ALMEIDA, 2013) e o diagrama horário da posição estudado em cinemática básica. Pelo relato de experiência exposto na monografia, a proposta mostrou-se eficiente, pois os resultados obtidos foram equivalentes ao esperado em outros conteúdos consagrados no currículo, mas Almeida (2013) admitiu que sua transposição precisava ser melhorada, sendo reproduzida mais vezes. Assim, a nova representação tem o potencial de facilitar a identificação, em um contexto educacional, de uma série de detalhes sobre a 
relatividade do movimento moderna graças à sua estrutura geométrica, mais concreta, e euclidiana.

Como o leitor pode reparar, a chave para compreender a representação geométrica baseada na eq. (2) é usar, independente do sistema de coordenadas espaciais escolhido, o tempo próprio como quarto eixo ortogonal, mas esse procedimento exige justificativas conceituais profundas. A correção na medida do espaço é uma propriedade primordial da relatividade clássica, pois a trajetória de um corpo pode mudar quando muda o referencial que a mede. Por exemplo, em uma situação ideal, um pulso luminoso movendo-se na perpendicular entre dois espelhos paralelos pode ser refletido indefinidamente; e esse sistema pode ser usado como relógio: o chamado relógio de luz. Se esse dispositivo for descrito em um outro referencial inercial que se move em paralelo aos espelhos, não é difícil perceber que a trajetória do pulso muda, inclinando-se e tornando-se mais longa. No caso de relógios analógicos de ponteiro, que são muito usados nas representações didáticas, o movimento do conjunto se compõe ao movimento circular de suas partes, cujas trajetórias são alongadas. No entanto, não haveria novidade em relação ao caso clássico se não fosse a imposição de um limite na composição de movimentos. É claro que o objetivo deste artigo não é tecer uma extensa discussão filosófica, mas, ao que parece, a constância do valor da velocidade da luz provoca um ajuste, sobretudo, no tempo. Essa é a grande novidade introduzida pela relatividade moderna e provavelmente decorre de uma "falha estrutural" do próprio instrumento de medida: Um relógio sempre foi concebido por partes em movimento cíclico, independente do modelo e da precisão, independente se o movimento é discreto ou contínuo, e o movimento do conjunto influencia no funcionamento do mecanismo interno. Isso vale para qualquer relógio, e a própria degradação térmica dos corpos é baseada em movimentos microscópicos, fazendo com que, nos seres vivos, por exemplo, o envelhecimento possa ser medido pelo chamado relógio biológico. Agora, na ausência de uma concepção melhor para compreender, em Filosofia Natural, o problema da mudança na Natureza, é possível contornar esse problema? Para contorná-lo, basta usar o conceito de dilatação temporal, mas isso não altera o fato de que a medida do tempo só vale para sistemas restritos, seja um corpo, seja um fenômeno físico específico.

Em um Universo em que tudo se move, fixar um conjunto de relógios sincronizados a um sistema de réguas só parece funcionar em pequena escala, então a nova abordagem euclidiana libera o tempo próprio para relacionar-se com qualquer sistema de coordenadas espacial; e, para fundamentá-la, será necessária alguma axiomatização. Machotka (2018), por exemplo, sugere três postulados para essa nova geometria: o primeiro define o espaço como tetradimensional e euclidiano, o segundo diz que as "tetravelocidades" são as mesmas para todos os corpos e o terceiro é incluído para dar conta de "estranhas características do espaço". No entanto, aqui, serão usados apenas dois postulados, adaptados dos princípios einstenianos, que se demonstrarão suficientes, junto a outros acessórios lógicos, até mesmo para explicar essas estranhezas. Ademais, por falar em "tetravelocidade" e em adaptações, seria possível 
usar os conceitos consagrados nas abordagens canônicas nessa nova abordagem? Ao que parece, por necessidade conceitual e da própria construção geométrica, somente termos ligados ao espaço, como posição, distância percorrida, deslocamento e "espaço próprio", ou as dimensões do corpo em repouso, podem ser usados sem risco. Já os termos ligados ao tempo, usados pelas abordagens canônicas, estão impregnados com a concepção de que esse conceito está ligado ao espaço; e até mesmo a expressão "tempo próprio" refere-se ao tempo medido por um relógio em repouso. Como nesta nova abordagem todos os tempos são "próprios", é suficiente apenas usar a palavra tempo para representar o que cada relógio mede, em repouso ou não.

Pensando do ponto de vista educacional, que é a verdadeira motivação deste trabalho, é importante que a linguagem matemática seja traduzida para o português, o que facilita seu uso em sala de aula. Será definido, neste artigo, o que é um instante, o que é um intervalo de tempo, ou duração do movimento, e o que é um evento, ou o par posição-instante; e o único cuidado que o leitor precisará ter é que esses conceitos estão relacionados à nova compreensão sobre o tempo. Também, essa geometria introduzirá um conceito análogo ao conceito de "linha de universo", que cumpre a mesma função, mas possui propriedades diferentes pela própria construção geométrica, que será chamado de história do movimento, ou o caminho tetradimensional percorrido entre dois eventos. Partindo deste último, será introduzido o conceito, sem qualquer correspondente nas abordagens canônicas, de período da história, s, ou o menor caminho entre dois eventos, de tal maneira que a eq. (2) é corretamente escrita como:

$$
\mathrm{d} s^{2}=\mathrm{d} w^{2}+\mathrm{d} x^{2}+\mathrm{d} y^{2}+\mathrm{d} z^{2} .
$$

A coordenada temporal $w$ é diretamente proporcional ao tempo do relógio comóvel ao objeto de estudo, mas o que significa $s$ ? A história e o período são propriedades cinemáticas próprias do movimento desse objeto e até podem, de alguma forma, relacionar-se com o tempo de um relógio tido em repouso, mas isso não só é facultativo, como pode ser irrelevante. Por exemplo, a vida média de um múon produzido na estratosfera é conhecida, bem como sua velocidade e sua distância média percorrida em relação a um sistema de coordenadas considerado em repouso em relação à superfície da Terra, logo, essas são informações suficientes para descrever o problema. Da mesma forma, em hipotéticas viagens interestelares tripuladas, por mais que as estrelas próximas estejam previamente mapeadas em relação ao Sistema Solar, durante uma longa viagem a velocidades comparáveis à da luz, o que realmente importa para a tripulação é o tempo medido por relógios na nave; e não aqueles medidos por relógios na Terra.

Nesse contexto, é possível aplicar a nova abordagem aos seis problemas propostos, que servem como laboratório para identificar as propriedades da nova geometria e permitem estudar as principais características da relatividade moderna sem introduzir conceitos mais complexos, como uma grandeza para medir a mudança do movimento e outras grandezas 
relacionadas à Dinâmica. Por sinal, a falta de minúcia e comedimento foi, provavelmente, o que levou Machotka (2018) a impor um terceiro postulado para a nova geometria, já que ele é sincero em afirmar que não entendeu as explicações físicas que levam às suas "estranhas características". Esses seis problemas, entre outros, fazem parte do processo histórico que consolidou a compreensão das próprias abordagens canônicas; e parece natural que eles também sejam usados para consolidar a nova abordagem. Contudo, como a História da Física foi evocada mais uma vez, vale a pena comentar que usar exemplos de inspiração histórica exige certas adaptações. Por exemplo, a atribuição de "paternidade" a uma equação ou a um problema pode até ser considerada uma prática elegante em alguns círculos acadêmicos, mas é perigosa, principalmente após a passagem de várias gerações. O desenvolvimento da TRE e da TET já é antigo o suficiente para apresentar discrepâncias em relação ao pensamento atual e ser enquadrado no campo histórico; e o possível anacronismo gerado na aprendizagem dos estudantes é temerário por atribuir uma descoberta fora de contexto. Graças a isso, será evitado, neste trabalho, o uso de termos como "transformação de Galileo", "transformações de Lorentz", "atraso de Poincaré", "paradoxo de Langevin" e "paradoxo de Ehrenfest". Não será muito difícil perceber, ao longo do texto, as correspondências com essas expressões, mas fazê-las nessa nova abordagem requer uma análise histórica meticulosa, que não é o objetivo aqui.

\section{Uma geometria euclidiana para o espaço tetradimensional}

Feita a apresentação das motivações que levaram ao uso dessa abordagem não tradicional e feito um breve apanhado histórico e conceitual sobre seu desenvolvimento, o objetivo doravante é fazer a ponte entre a compreensão física e a nova representação geométrica, que é, por sua vez, baseada em um tempo ligado ao corpo e/ou ao fenômeno físico a ser estudado; e não ao espaço. Nesta seção, será oferecido ao leitor um formalismo matemático mínimo, que será contextualizado, nas próximas seções, a partir dos problemas previamente selecionados. Será assumido de forma muito pragmática que existe um espaço vetorial tetradimensional $\mathbb{H}$, extensão do $\mathbb{R}^{3}$, em que um ponto material livre da interação com outros corpos é descrito em repouso ou em movimento retilíneo e uniforme (MRU). Esse objeto abstrato pode ser chamado, estendendo-se o conceito clássico, de referencial inercial e existem incontáveis deles de tal maneira que:

Postulado 1: Todos os referenciais inerciais são capazes, de forma equivalente, de descrever o fenômeno do movimento.

Essa equivalência, no sentido usado aqui, refere-se à conformidade na descrição matemática e na manutenção do conceito físico de encontro, ou seja, os corpos estão tão próximos que as incertezas nas medidas, causadas pela distância entre eles, tornam-se desprezíveis. 
Considerando $c$ uma constante e $t$ o tempo medido por um relógio contíguo ao objeto de estudo cujo movimento/repouso se pretende representar, um referencial $\mathbb{H}$ pode ter sua representação analítica dada por um sistema de coordenadas cartesianas, que é expresso pelo quarteto ordenado $(w ; x ; y ; z)$, sendo $x, y, z$, as coordenadas espaciais, e $w$, a coordenada temporal, definida como:

$$
w=c t .
$$

Como um problema pode ter vários desses objetos e, por conseguinte, vários relógios comóveis, é conveniente usar um símbolo diferente para o tempo medido por cada um deles, como $t, \tau, \mathrm{T}$, etc., e cada relógio se comporta de forma diferente de tal maneira que não se pode definir um tempo único e comum a todos. Assim, é possível definir $\mathbf{w}=(w ; 0 ; 0 ; 0)$ como um instante e $\Delta \mathbf{w}$ como a duração do movimento de um ponto material, implicando, considerando o tempo igual para qualquer sistema de coordenadas espacial e tomando $w^{\prime}$ pertencente a um outro referencial arbitrário $\mathbb{H}^{\prime}$, na isometria das durações:

$$
\mathrm{d} \mathbf{w}^{\prime}=\mathrm{d} \mathbf{w}
$$

Sendo $\mathrm{r}=(0 ; x ; y ; z)$ a posição de um ponto material descrito no referencial $\mathbb{H} \mathrm{e}$ tomando $\mathbf{s}=\mathbf{w}+\mathbf{r}$ como o evento, é possível, usando a métrica dada pela eq. (3) e sabendo que $\Delta \mathbf{r}$ é o deslocamento e $\Delta \mathbf{s}$ é seu periodo, definir as normas:

$$
\begin{aligned}
& \|\mathrm{d} \mathbf{r}\|=\sqrt{\mathrm{d} x^{2}+\mathrm{d} y^{2}+\mathrm{d} z^{2}} \equiv \mathrm{d} r, \\
& \|\mathrm{~d} \mathbf{s}\|=\sqrt{\mathrm{d} w^{2}+\mathrm{d} r^{2}} \quad \equiv \mathrm{d} s .
\end{aligned}
$$

A sucessão de eventos de um ponto material pode ser chamada de história, $h$, e as Fig. 1a e 1b, denominadas mapas bidimensionais do espaço-tempo, ilustram um mesmo exemplo de movimento para o caso em que $\mathbf{s}=\left(w ; x ; y_{0} ; z_{0}\right)$, com $y_{0}$ e $z_{0}$ constantes. Nesse contexto, é possível definir, também, as grandezas cinemáticas velocidade, $\mathbf{v}$, covelocidade, $\mathbf{u}$, e celeridade, q, como:

$$
\begin{aligned}
& \mathbf{v}=c \frac{\mathrm{d} \mathbf{r}}{\mathrm{d} s} \\
& \mathbf{u}=c \frac{\mathrm{d} \mathbf{w}}{\mathrm{d} s} \\
& \mathbf{q}=c \frac{\mathrm{d} \mathbf{s}}{\mathrm{d} w},
\end{aligned}
$$

em que ds pode estar, segundo a conveniência, relacionado ao intervalo de tempo medido por um relógio em repouso no referencial adotado. 


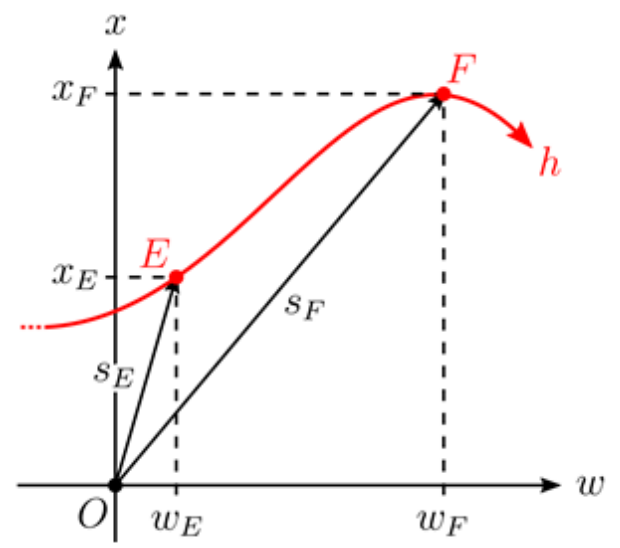

(a) Em termos de coordenadas.

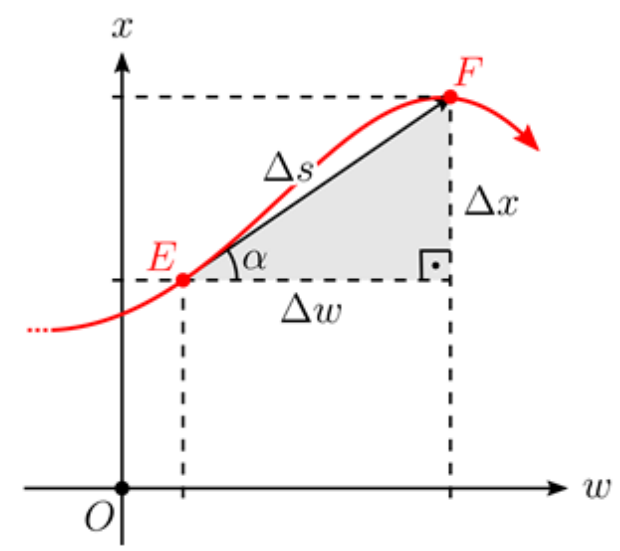

(b) Em termos de intervalos.

Fig. 1 - Um exemplo de mapa bidimensional do espaço-tempo que representa dois eventos, E e F, da história do movimento (em vermelho) de um ponto material.

As eq. (7a), (7b) e (7c) também podem ser reescritas nas suas formas trigonométricas ao tomar $\alpha$ o ângulo que mede a inclinação do elemento de período a partir do eixo $w$ :

$$
\begin{aligned}
& \mathbf{v}=c \operatorname{sen}(\alpha) \frac{\mathrm{d} \mathbf{r}}{\mathrm{d} r}, \\
& \mathbf{u}=c \cos (\alpha) \frac{\mathrm{d} \mathbf{w}}{\mathrm{d} w}, \\
& \mathbf{q}=c\left[\frac{d \boldsymbol{w}}{d w}+\operatorname{tg}(\alpha) \frac{d r}{d r}\right] .
\end{aligned}
$$

Essas expressões trigonométricas levam às relações:

$$
\begin{aligned}
& u^{2}+v^{2}=c^{2}, \\
& q=\frac{c^{2}}{u},
\end{aligned}
$$

com $u$, a norma da covelocidade, $v$, a norma da velocidade, e $q$, a norma da celeridade. Como $c$ ainda é uma constante desconhecida, é possível postular que:

Postulado 2: A norma da covelocidade da luz no vácuo, $u_{\gamma}$, é nula para qualquer referencial inercial, resultando em:

$$
c=v_{\gamma}
$$

ou seja, c corresponde à norma da velocidade da luz no vácuo e é um invariante sob transformações entre referenciais.

Uma vez definidas a métrica, dada pela eq. (3), e a isometria, dada pela eq. (5), é fácil perceber que a transformação entre dois referenciais deve satisfazer a seguinte relação:

$$
\mathrm{d} s^{2}-d x^{2}-d y^{2}-d z^{2}=\mathrm{d} s^{\prime 2}-d x^{\prime 2}-d y^{\prime 2}-d z^{\prime 2},
$$


com $s^{\prime}, x^{\prime}, y^{\prime}$ e $z^{\prime}$ pertencentes a um referencial $\mathbb{H}^{\prime}$ arbitrário. Uma solução particular para essa relação, no caso em que $x^{\prime}$ se move paralelamente a $x$ e tomando $\mathrm{v}$ e u respectivamente como as componentes não nulas da velocidade e da covelocidade relativas entre os dois referencias, é:

$$
\begin{aligned}
\mathrm{d} s^{\prime} & =\frac{c}{\mathrm{u}}\left(\mathrm{d} s-\frac{\mathrm{v}}{c} \mathrm{~d} x\right), \\
\mathrm{d} x^{\prime} & =\frac{c}{\mathrm{u}}\left(\mathrm{d} x-\frac{\mathrm{v}}{c} \mathrm{~d} s\right), \\
\mathrm{d} y^{\prime} & =\mathrm{d} y, \\
\mathrm{~d} z^{\prime} & =\mathrm{d} z .
\end{aligned}
$$

Sabendo que a velocidade pode ser descrita em termos de componentes como $\mathbf{v}=\left(0 ; v_{x} ; v_{y} ; v_{z}\right)$, as composições de velocidades e covelocidades são:

$$
\begin{aligned}
& u^{\prime}=\left(1-\frac{\mathrm{v}}{c} \frac{u_{x}}{c}\right)^{-1}\left(\frac{\mathrm{u}}{\mathrm{c}} \mathrm{u}\right), \\
& v_{x}^{\prime}=\left(1-\frac{\mathrm{v}}{c} \frac{u_{x}}{c}\right)^{-1}\left(v_{x}-\mathrm{v}\right), \\
& v_{y}^{\prime}=\left(1-\frac{\mathrm{v}}{c} \frac{u_{x}}{c}\right)^{-1}\left(\frac{\mathrm{u}}{\mathrm{c}} v_{y}\right), \\
& v_{z}^{\prime}=\left(1-\frac{\mathrm{v}}{c} \frac{u_{x}}{c}\right)^{-1}\left(\frac{\mathrm{u}}{\mathrm{c}} v_{z}\right) .
\end{aligned}
$$

com $u^{\prime}, v_{x}^{\prime}, v^{\prime}{ }_{y}, v_{z}^{\prime}$ pertencentes ao referencial $\mathbb{H}^{\prime}$. Essas composições não só são coerentes com o Postulado 2, pois a norma da velocidade de um pulso luminoso não se altera quando submetidas a elas, como também implica que $c$ é um valor máximo para as velocidades no Universo.

\section{Problema 1: A dilatação do tempo}

O primeiro problema que será proposto, aqui, consiste em encontrar a relação entre os tempos medidos por relógios em movimento relativo entre si e como representá-la usando a nova geometria. Para tanto, será considerada a situação em que uma nave passa próximo, com velocidade constante de norma $v_{n}$, a uma estação espacial, que é considerada em repouso. Dentro da nave está Beatriz e seu relógio, enquanto na estação está Amanda e outro relógio. Uma fonte laser situada no piso do compartimento de carga da nave emite, posição $F$ na Fig. 2a, um pulso luminoso que, pouco depois, alcança um receptor de luz no teto e é detectado por este, posição $R$ na Fig. 2b. Para Amanda, o intervalo de tempo entre a emissão e a detecção é dado por $\Delta t$ e, assumindo que $c$ é um invariante, o deslocamento do pulso é dado pelo segmento $\overline{O R}$, de comprimento $c \Delta t$, enquanto a nave se desloca uma distância $v_{n} \Delta t$. Por outro lado, para Beatriz, o intervalo de tempo entre a emissão e a detecção é $\Delta \tau$ e o pulso é medido em uma trajetória perpendicular ao piso do compartimento de carga, como é indicado 
pelo seguimento tracejado $\overline{F R}$, de comprimento $c \Delta \tau$. Pelo triângulo retângulo $\Delta_{O F R}$ apresentado na Fig. 2b, é possível deduzir a relação entre os intervalos de tempo medidos pelos dois relógios:

$$
\Delta \tau=\Delta t \sqrt{1-\left(\frac{v_{n}}{c}\right)^{2}}
$$

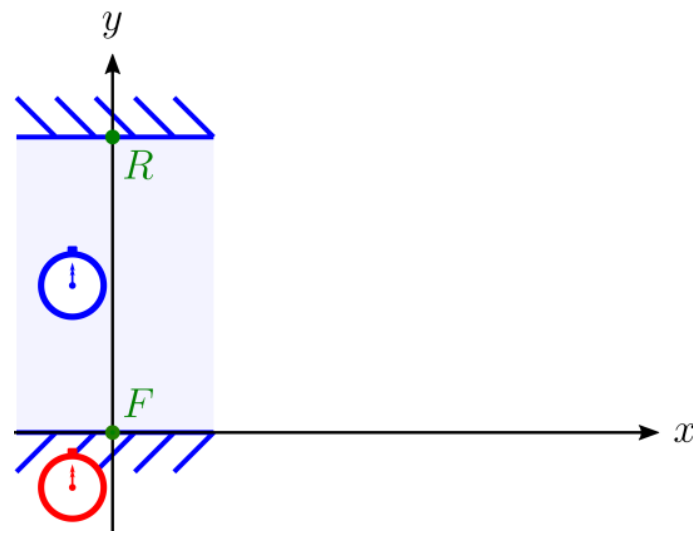

(a) A emissão do pulso.

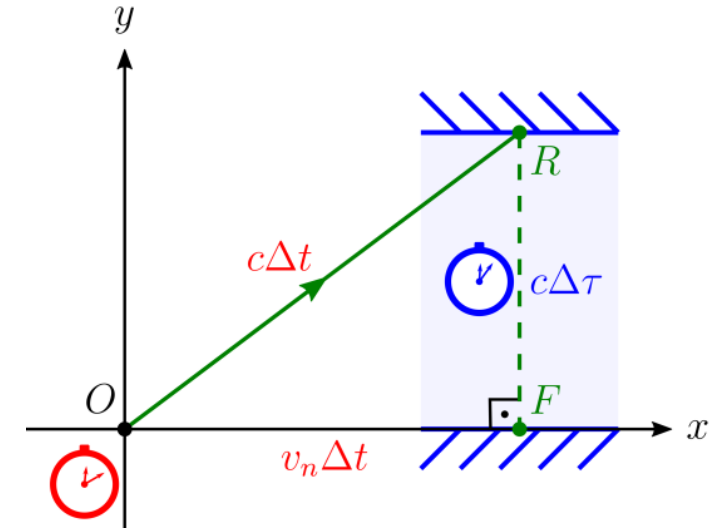

(b) A detecção do pulso.

Fig. 2 - Visão esquemática da trajetória seguida pelo pulso luminoso (em verde). $O$ relógio azul marca o tempo da nave e o vermelho, o tempo da estação.

Nesse contexto, para além da existência de dois relógios comóveis a dois corpos distintos, é fundamental identificar que o fenômeno físico em questão é a emissão e a detecção do pulso luminoso dentro da nave. A partir da eq. (14), é possível perceber que, como $0 \leq \sqrt{1-\left(\frac{v_{n}}{c}\right)^{2}} \leq 1, \Delta \tau$ é menor que $\Delta t$ para todo $v_{n}$ não nulo, ou seja, que o relógio dentro da nave é "mais devagar" que o relógio na estação, o que é normalmente conhecido como dilatação temporal e ocorre porque todo relógio é o resultado do movimento de suas partes constituintes, como foi comentado anteriormente. Contudo, o enunciado deste problema carrega consigo, de forma implícita, a concepção de que o tempo está necessariamente relacionado ao espaço por um relógio fixo ao sistema de coordenadas, o que pode gerar confusão, pois, se a emissão e a detecção do pulso luminoso ocorressem dentro da estação, o resultado da eq. (14) seria invertido e o relógio usado por Amanda é que seria "mais devagar" que o relógio usado por Beatriz. Como a chave da compreensão deste problema está, não só nos tempos medidos pelos relógios comóveis, como também, e sobretudo, no fenômeno físico estudado, pelo breve formalismo desenvolvido na seção anterior, será considerado i) que a estação é descrita em repouso no referencial $\mathbb{H}$, ii) que a nave se move paralelamente ao seu eixo $x$, iii) que os dois relógios estão convenientemente zerados no ato de emissão do pulso e iv) que essa emissão é um encontro e corresponde ao evento-origem, $O$, mostrado nas Fig. $3 \mathrm{a}$ e $3 \mathrm{~b}$. Este último conceito engloba a origem do 
sistema de coordenadas espaciais mostrado nas Fig. 2a e 2b. Pela definição da coordenada temporal dada pela eq. (4) e pela isometria dada pela eq. (5), a detecção do pulso ocorre quando a estação e a nave estão, respectivamente, nos instantes de coordenadas:

$$
\begin{aligned}
& w_{E}=c t_{\text {detecção }}, \\
& w_{N}=c \tau_{\text {detecção }},
\end{aligned}
$$

com $w_{E}$ igual ao valor da duração do movimento da estação, $\Delta w_{e}$, e $w_{N}$ igual ao valor da duração do movimento da nave, $\Delta w_{n}$.

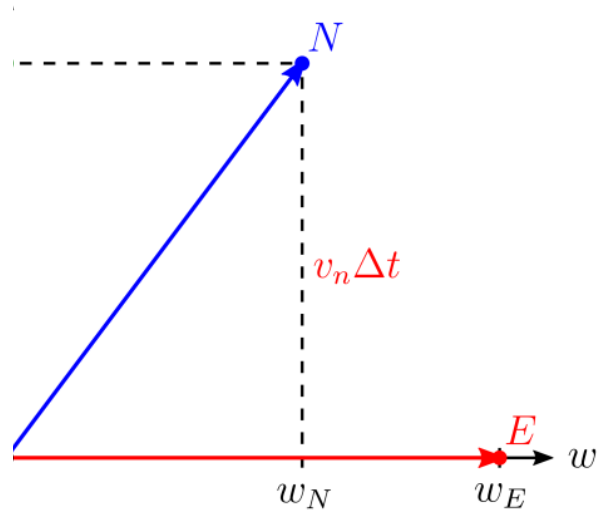

(a)

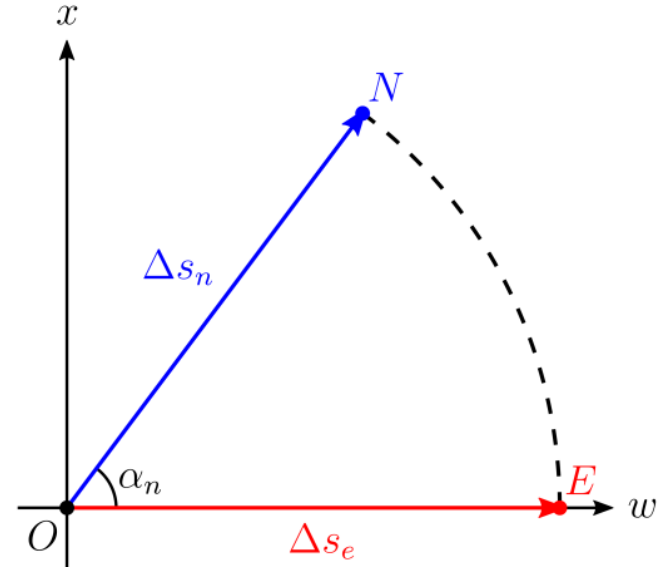

(b)

Fig. 3 - Mapa bidimensional do espaço-tempo do referencial $\mathbb{H}$ para os movimentos da nave (em azul) e da estação (em vermelho) tomadas como pontos materiais.

Usando a relação entre a velocidade e a covelocidade dada pela eq. (9a) e a forma trigonométrica da covelocidade dada pela eq. (8b), é fácil reescrever a eq. (14) como:

$$
\Delta w_{n} \equiv \Delta w_{e} \cos \left(\alpha_{n}\right),
$$

em que $\alpha_{n}$ mede a inclinação do período da nave, de norma $\Delta s_{n}$, que é congruente à sua história por este ser um MRU. Com isso, não é muito difícil perceber que:

$$
\Delta s_{n} \equiv \Delta s_{e} \equiv \Delta w_{e}
$$

sendo $\Delta s_{e}$ a norma do período do movimento da estação; como mostra, na Fig. 3b, o arco de circunferência centrada em $O$. Em suma, a eq. (17) já dá o primeiro indício de que a história do movimento de um corpo pode se relacionar com o tempo medido por um relógio em outro corpo em repouso no referencial adotado. Outrossim, essa equação permite identificar que os eventos $E$ e $N$, atravessados pela circunferência de simultaneidade tracejada, são considerados simultâneos neste referencial $\mathbb{H}$; e o conceito de simultaneidade é diferente do conceito de encontro, pois assume a ideia de eventos a uma distância não desprezível, o que pode causar problemas, como será visto nas próximas seções.

Este problema permite, ainda, discutir os dois casos limites para o movimento da 
nave. O primeiro, conhecido como limite clássico, representa o caso em que $v_{n}$ é muito menor que $c$, que é a mesma coisa que considerar $\alpha_{n}$ tendendo a zero. É fácil perceber, tanto pela eq. (14), quanto pela Fig. 4a, que $\Delta t$ e $\Delta \tau$ são aproximadamente iguais a um mesmo valor, o chamado "tempo comum" intuído no cotidiano, fazendo com que o conceito de velocidade definido pela eq. (7a) seja escrito em sua forma clássica: $\mathbf{v}=\frac{\mathrm{d} \mathbf{r}}{\mathrm{d} t}$. Já no segundo caso, a Fig. $4 \mathrm{~b}$ mostra a situação em que a nave se move com $v_{n}$ tendendo a $c$; e a dilatação dos períodos se torna evidente, tendo suas normas tendendo a infinito desde que $\Delta w_{n}$ tenha um valor fixo e diferente de zero. Por outro lado, ao que parece, somente o movimento da luz possui uma duração sempre nula, permitindo que o seu período seja representado por um segmento de reta vertical e finito no mapa bidimensional do espaço-tempo e levando a uma interpretação curiosa: A luz possui um movimento puramente espacial e carrega a exata informação do instante em que foi emitida, mas esse é um assunto que será retomado na discussão sobre o paradoxo aparente dos gêmeos.

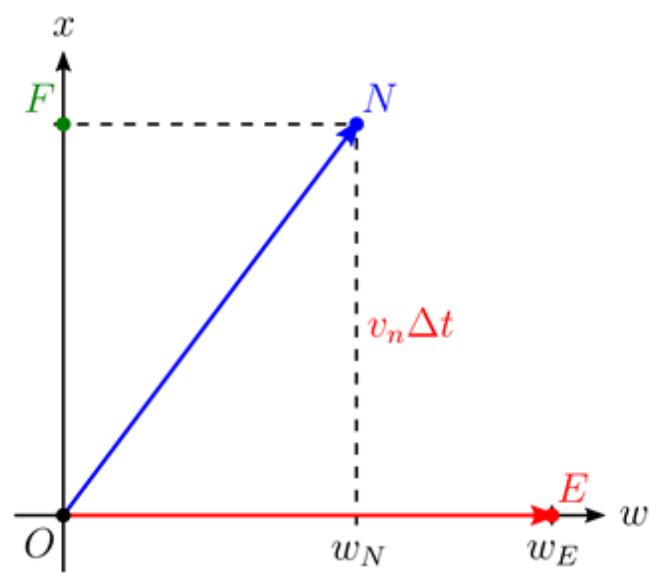

(a) $u_{B} \approx c$ ou $v_{B} \ll c$.

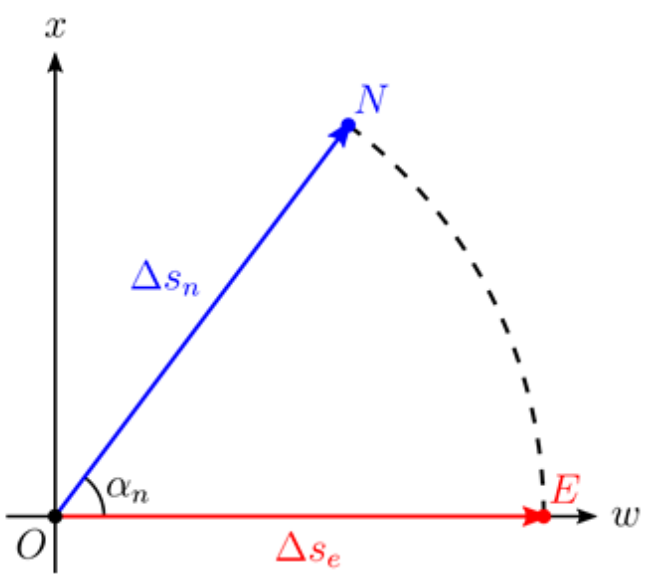

(b) $u_{n} \ll c$ ou $v_{n} \approx c$.

Fig. 4 - Casos limites.

\section{Problema 2: A composição de movimentos}

O objetivo nesta seção, por sua vez, é estudar a composição de movimentos de tal maneira que, dado o enredo do problema anterior, será considerada a nova situação em que a estação se move com velocidade constante de norma $v_{e}^{\prime}$ e a nave, com uma velocidade constante de norma $v_{n}^{\prime}$, ambas na mesma direção e no mesmo sentido conforme mostra a Fig. 5. Seus deslocamentos, com respectivos comprimentos $\Delta x_{e}^{\prime}$ e $\Delta x_{n}^{\prime}$, podem ser obtidos a partir das durações dos movimentos medidas com base nos relógios de Amanda e Beatriz ou pelo intervalo de tempo, medido por um terceiro relógio qualquer, considerado, agora, em repouso, o que leva a um grande problema: Não só os tempos medidos pelos dois primeiros 
relógios são diferentes, como também o fenômeno da dilatação temporal depende da velocidade, como mostra a eq. (14). Como a estação e a nave não possuem velocidades iguais,

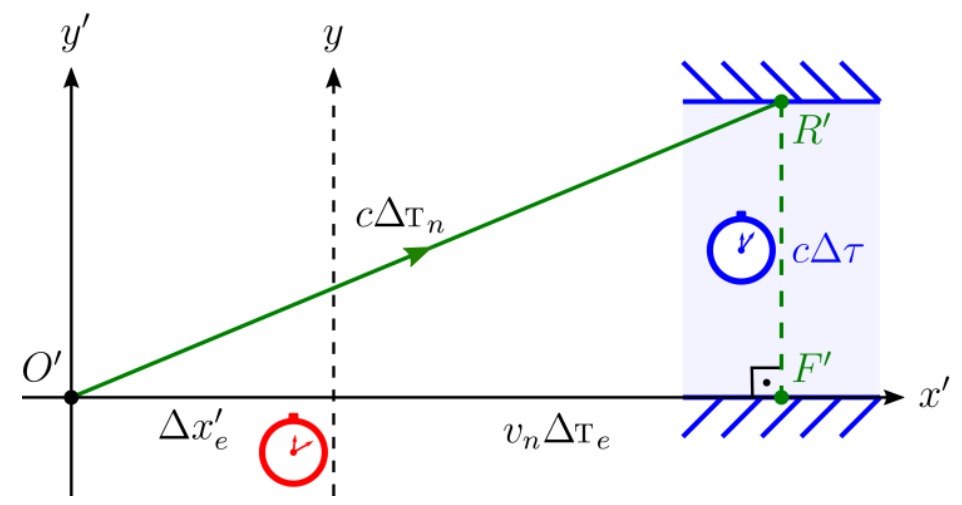

Fig. 5 - Visão esquemática da nova trajetória seguida pelo pulso luminoso (em verde). O relógio azul marca o tempo da nave e o vermelho, o da estação.

os intervalos de tempo, respectivamente $\Delta \mathrm{T}_{e}$ e $\Delta \mathrm{T}_{n}$, medidos pelo terceiro relógio, devem ser, via de regra, diferentes, de tal maneira que:

$$
\begin{gathered}
\Delta t=\Delta \mathrm{T}_{e} \sqrt{1-\left(\frac{v_{e}^{\prime}}{c}\right)^{2}}, \\
\Delta \tau=\Delta \mathrm{T}_{n} \sqrt{1-\left(\frac{v_{n}^{\prime}}{c}\right)^{2}} .
\end{gathered}
$$

A distância percorrida pelo pulso luminoso é dada pelo segmento $(\overline{O R})^{\prime}$, de comprimento $c \Delta \mathrm{T}_{n}$, enquanto a nave se desloca com $\Delta x_{n}^{\prime}$ igual a $v_{n}^{\prime} \Delta \mathrm{T}_{n}$. Por outro lado, esse deslocamento pode ser entendido, também, como a composição entre o deslocamento da estação, de comprimento $\Delta x^{\prime}{ }_{e}$, e a "correção", pela eq. (18a), da distância percorrida pela nave na Fig. 2b, ou seja:

$$
\Delta x_{n}^{\prime}=\Delta x_{e}^{\prime}+v_{n} \Delta \mathrm{T}_{e} .
$$

A partir do triângulo retângulo $\Delta_{(O F R)}$, mostrado na Fig. 5 e da relação entre $\Delta \tau$ e $\Delta \mathrm{T}_{e}$ resultante da composição entre as eq. (14) e (18a), é possível encontrar a relação entre os dois intervalos de tempo medidos pelo pretenso relógio em repouso:

$$
\Delta \mathrm{T}_{n}=\Delta \mathrm{T}_{e}+\frac{v_{n}}{c^{2}} \Delta x_{e}^{\prime},
$$

em que a parcela $\frac{v_{n}}{c^{2}} \Delta x^{\prime}{ }_{e}$ é chamada de atraso entre as duas medidas. Finalmente, pela razão entre as eq. (19) e (20) e sabendo que $\Delta x_{e}^{\prime}$ é igual a $v_{e}^{\prime} \Delta \mathrm{T}_{e}$, a composição de velocidades é dada por:

$$
v_{n}^{\prime}=\left(1+\frac{v_{n}}{c} \frac{v_{e}^{\prime}}{c}\right)^{-1}\left(v_{n}+v_{e}^{\prime}\right)
$$

Talvez, a hipótese de dois intervalos de tempo diferentes assumida para o terceiro 
relógio possa provocar estranheza. As Fig. 2a, 2b e 5 mostram que a trajetória do pulso luminoso muda, inclinando-se progressivamente para a direita e tornando-se cada vez mais longa conforme a velocidade da nave aumenta; e essa composição de movimentos é o que afeta individualmente a medida dos relógios, como já discutido na apresentação históricoconceitual deste artigo. Contudo, é possível contornar esse problema e corrigir a medida do tempo usando o fenômeno da dilatação temporal para cada relógio em particular, como foi feito para se deduzir a eq. (19). Por sinal, é normal que o leitor não reconheça imediatamente as eq. (19) e (20), mas não é muito difícil reformulá-las usando a eq. (18a), levando-as respectivamente às suas formas mais usuais:

$$
\begin{aligned}
& \Delta \mathrm{T}_{n}=\left(1-\frac{\mathrm{v}^{2}}{c^{2}}\right)^{-\frac{1}{2}}\left(\Delta t-\frac{\mathrm{v}}{c^{2}} \Delta x_{n}\right), \\
& \Delta x_{n}^{\prime}=\left(1-\frac{\mathrm{v}^{2}}{c^{2}}\right)^{-\frac{1}{2}}\left(\Delta x_{n}-\mathrm{v} \Delta t\right),
\end{aligned}
$$

em que $\mathrm{v}=-v^{\prime}{ }_{e}$ e corresponde à componente não nula da velocidade relativa entre os dois referencias.

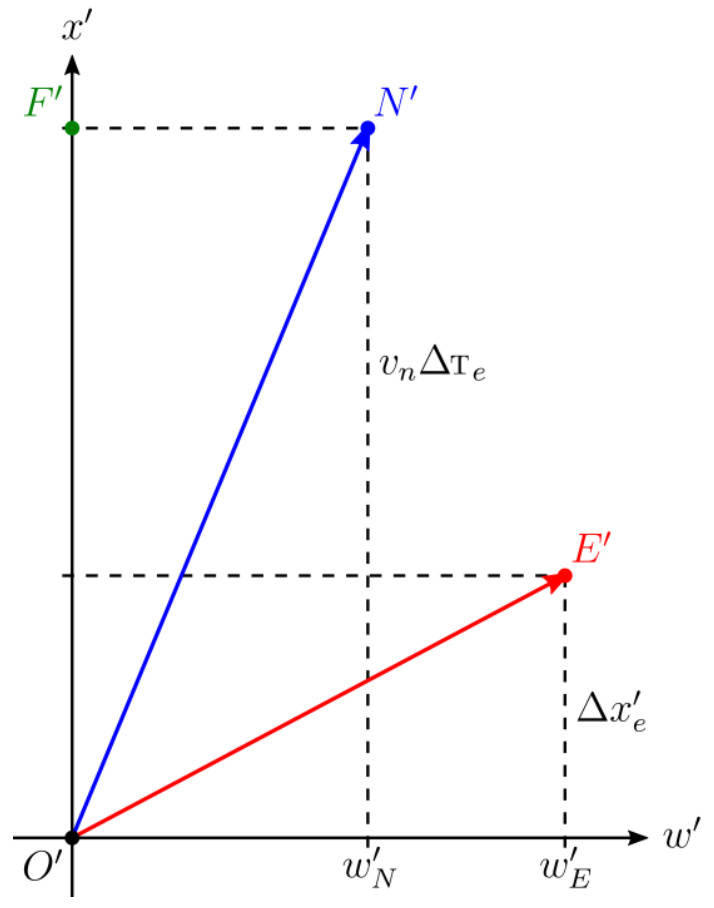

(a)

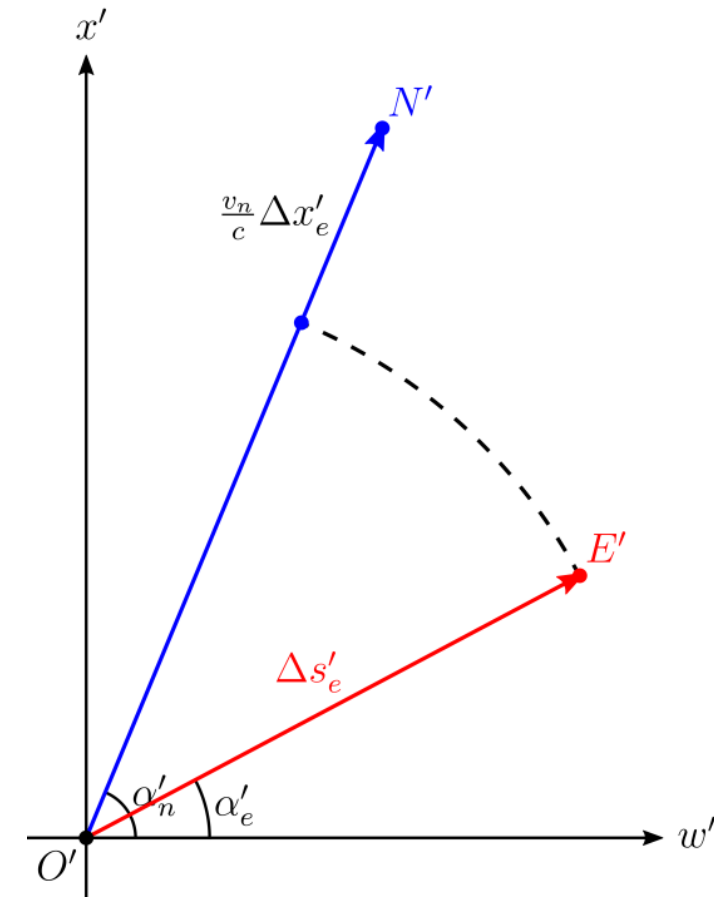

(b)

Fig. 6 - Mapa, no referencial $\mathbb{H}^{\prime}$, dos movimentos da nave (em azul) e da estação (em vermelho) como pontos materiais.

Uma vez entendido que a relatividade moderna implica em correções tanto na medida do espaço, quanto na do tempo, os movimentos da estação e da nave podem ser representados no novo referencial $\mathbb{H}^{\prime}$, conforme mostram as Fig. 6a e 6b. Em princípio, a 
história do movimento do terceiro relógio, dito em repouso, também deveria ser representada nas figuras, mas, como os objetos de estudo são a nave e a estação, esse procedimento é opcional e até mesmo irrelevante se for considerado que as eq. (19), (20), (26a) e (26b) podem ser reescritas de tal forma que:

$$
\begin{aligned}
& \Delta s^{\prime}{ }_{e}=c \Delta \mathrm{T}_{e}, \\
& \Delta s_{n}^{\prime}=c \Delta \mathrm{T}_{n}, \\
& \Delta s_{n}^{\prime}-\Delta s^{\prime}{ }_{e}=\frac{v_{n}}{c} \Delta x^{\prime}{ }_{e}, \\
& \frac{c}{u_{n}}=\left(1-\frac{v^{2}}{c^{2}}\right)^{-\frac{1}{2}} .
\end{aligned}
$$

A circunferência de simultaneidade tracejada na Fig. $6 \mathrm{~b}$ evidencia que os eventos $N^{\prime}$ e $E^{\prime}$ não são considerados simultâneos, apesar de seus análogos em $\mathbb{H}$ o serem; e a simultaneidade variar, via de regra, de um referencial para outro é uma propriedade marcante da relatividade moderna e relaciona-se à incerteza causada pelas medidas fora da vizinhança imediata dos eventos. Isso justifica uma Física baseada no conceito de encontro; e não no de simultaneidade. Pela Fig. 6a, tanto a eq. (18b), quanto as eq. (26a) e (26b), satisfazem a relação:

$$
\Delta s_{n}^{2}-\Delta x_{n}^{2}=\Delta s_{n}^{\prime 2}-\Delta x_{n}^{\prime 2},
$$

enquanto a eq. (18a), para $\Delta x_{e}=0$, resulta em:

$$
\Delta s_{e}^{2}=\Delta s_{e}^{\prime 2}-\Delta x_{e}^{\prime 2}
$$

Considerando o limite clássico, em que $\Delta \mathrm{T}_{e}, \Delta \mathrm{T}_{n}$ e $\Delta \tau$ são aproximadamente iguais ao $\Delta t$, que pode ser tomado como o "tempo comum", a transformação para o movimento da nave leva em consideração apenas a correção na medida do espaço e é escrita como:

$$
\begin{aligned}
& \Delta s_{n}^{\prime}=c \Delta t, \\
& \Delta x_{n}^{\prime}=\Delta x_{n}-\mathrm{v} \Delta t .
\end{aligned}
$$

\section{Problema 3: A contração do comprimento}

Neste problema, que visa estudar as consequências do conceito de simultaneidade sobre a medida do comprimento de um corpo extenso e sua representação usando a abordagem geométrica sugerida aqui, será proposto que a nave onde viaja Beatriz passa próximo à estação onde está Amanda conforme o Problema 1. Contudo, agora, o pulso luminoso é emitido por uma fonte na parede anterior do compartimento de carga e detectado por um receptor na parede posterior de tal maneira que sua trajetória é dada pelo segmento $\overline{O R}$ mostrado na Fig. 7. Pelo mesmo procedimento que resultou nas eq. (19) e (20), o compri- 


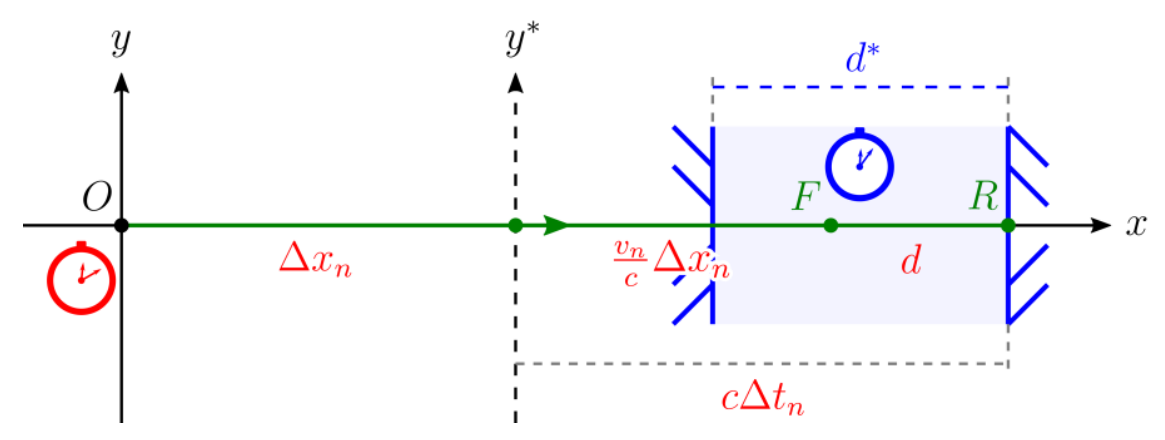

Fig. 7 - Trajetória seguida pelo pulso luminoso (em verde) entre sua emissão, ponto $O$, e sua detecção, ponto $R$. Mais uma vez, o relógio azul marca o tempo da nave e o vermelho, o da estação.

mento da trajetória do pulso, $\Delta x_{\gamma}$, pode ser entendido como a composição entre seu movimento e o movimento da nave, ou:

$$
\Delta x_{\gamma}=\Delta x_{n}+c \Delta t_{n}
$$

enquanto o intervalo entre a emissão e a detecção, $\Delta t_{\gamma}$, medido pelo relógio na estação é:

$$
\Delta t_{\gamma}=\Delta t_{n}+\frac{1}{c} \Delta x_{n}
$$

cujo termo $\frac{1}{c} \Delta x_{n}$ é o atraso.

Usualmente, o entendimento sobre a medida de comprimento decorre da distância entre dois pontos considerados ao "mesmo tempo" e é bastante óbvio que a emissão e a detecção do pulso não podem ser consideradas simultâneas, nem para Beatriz, nem para Amanda. Assim, em relação ao relógio na estação, o comprimento do compartimento de carga, $d$, representado pelo segmento $\overline{F R}$, deve ser aferido considerando o atraso na medida do tempo; e, neste intervalo, a parede anterior percorreu uma distância adicional de $\frac{v_{n}}{c} \Delta x_{n}$. Assim, sabendo que:

$$
\mathrm{c} \Delta t_{n}=\frac{v_{n}}{c} \Delta x_{n}+d,
$$

como mostra a Fig. 7, que $\Delta x_{n}$ é igual a $v_{n} \Delta t_{n}$ e que $\Delta \tau$ e $\Delta t_{n}$ se relacionam segundo a eq. (14), é fácil obter a relação entre $d$ e o comprimento medido usando o relógio de Beatriz, $d^{*}$ :

$$
d=d^{*} \sqrt{1-\left(\frac{v_{n}}{c}\right)^{2}}
$$

resultado, este, amplamente conhecido como contração do comprimento, pois $d$ é sempre menor que $d^{*}$ para todo $v_{n}$ não nulo, como compara a Fig. 7. Por outro lado, mesmo que, de fato, o atraso medido por Amanda não seja relevante para Beatriz, tem-se que seu equivalente medido pelo relógio na nave, $\Delta \tau_{a t}$, pode ser escrito como: 


$$
\Delta \tau_{a t}=-\frac{v_{n}}{c}\left[1-\left(\frac{v_{n}}{c}\right)^{2}\right]^{-\frac{1}{2}} d,
$$

cujo sinal negativo indica que a posição da parede anterior do compartimento de carga é considerada no "futuro" em relação à da parede posterior.

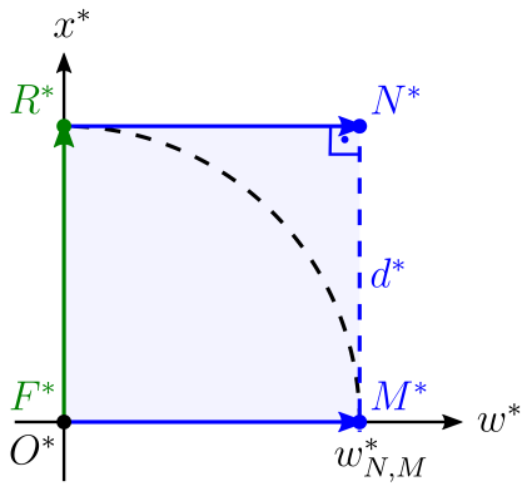

Fig. 8 - Mapa, no referencial $\mathbb{H}^{*}$, dos movimentos da nave (limitada em azul) e do pulso luminoso (em verde).

É fundamental perceber, mais uma vez, que o fenômeno físico sob estudo é a detecção e a emissão do pulso luminoso dentro da nave e que, caso esse fenômeno ocorresse dentro da estação, o resultado da contração do comprimento seria invertido. Já para a representação geométrica deste problema, não é necessário explicitar o movimento da estação e é interessante delimitar o comprimento do compartimento de carga por suas extremidades, que são apresentadas como pontos materiais com histórias paralelas, como mostra a Fig. 8. No referencial $\mathbb{H}^{*}$, em que a nave é descrita em repouso, os movimentos das paredes anterior e posterior seguem histórias horizontais no mapa do espaço-tempo, enquanto a distância percorrida pelo pulso luminoso é um período vertical de comprimento equivalente ao do compartimento de carga, $d^{*}$, que também é equivalente à duração do avanço da nave no tempo medido pelo relógio de Beatriz, $\Delta w_{n}^{*}$. Assim, considerando i) a emissão como o evento-origem, $O^{*}$, ii) a detecção como o encontro representado pelo par de eventos correspondentes $R^{*}$, pertencente à história do pulso, e $N^{*}$, pertencente à história da parede posterior, e iii) $M^{*}$ como o evento simultâneo à detecção sobre a história da parede anterior, é possível formar o quadrado :..: $(\text { ORNM })^{*}$, Fig. 8.

Como o leitor pode ter notado, curiosamente, a detecção nesta representação geométrica é um encontro separado em dois eventos distintos, mesmo que correspondentes, com a mesma coordenada espacial e em instantes diferentes; e esta é outra estranha consequência da construção desta geometria, sendo uma propriedade fundamental para a posterior compreensão dos três paradoxos aparentes mencionados na seção introdutória deste artigo. Entrementes, no referencial $\mathbb{H}$, em que a estação é descrita em repouso, essas extremi- 


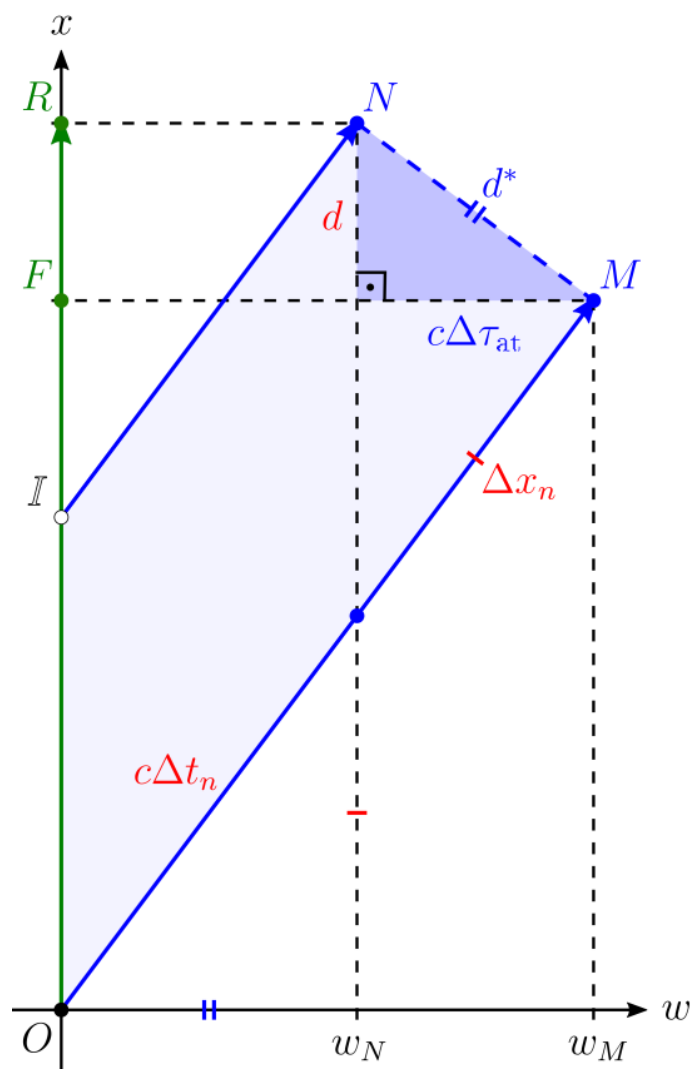

(a)

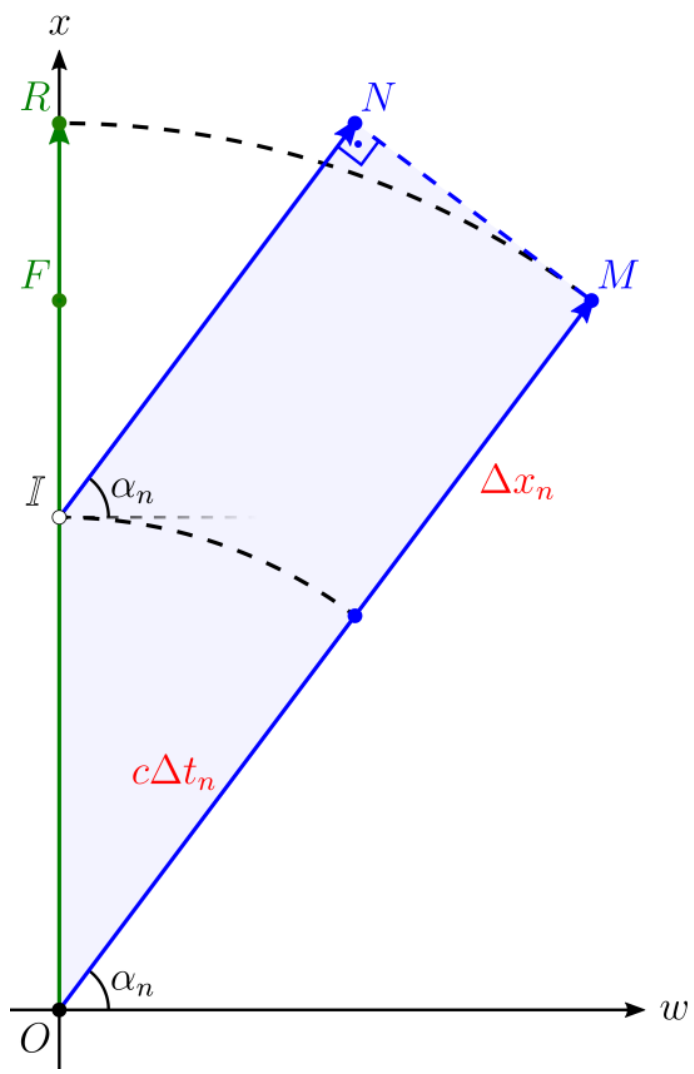

(b)

Fig. 9 - Mapa, no referencial $\mathbb{H}^{\prime}$, dos movimentos da nave (em azul) e da estação (em vermelho) como pontos materiais.

dades são inclinadas em um ângulo $\alpha_{n}$, Fig. 9b, enquanto o pulso percorre uma distância maior dada pela eq. (30), sendo detectado no evento $R$ pertencente à sua história. $\mathrm{O}$ quadrado : $(O R N M)^{*}$ é cisalhado em um paralelogramo o qual pertencem os eventos $O$, a emissão do pulso, e $N$, o correspondente à sua detecção sobre a história da parede posterior, como mostra a Fig. 9a. Pela isometria dada pela eq. (5), $\Delta w_{n}^{*}$ é igual a $\Delta w_{n}$, que é, por sua vez, igual ao valor $w_{N}$. Contudo, a mudança de referencial implica em um atraso no tempo que não existia inicialmente para Beatriz e, como mostra a Fig. 9b, o evento simultâneo ao $N$ sobre a história da parede anterior do compartimento de carga passa a ser $M$, pois ela avança uma distância $\frac{v_{n}}{c} \Delta x_{n}$ nesse intervalo de tempo. Nessas condições, talvez com alguma estranheza, é possível identificar cinco propriedades fundamentais da nova geometria apresentada aqui: i) os eventos $R$ e $N$ correspondem ao mesmo encontro, possuem a mesma componente $x$, mas não são congruentes; ii) duas histórias podem se cruzar, evento $I$, sem que isso signifique um encontro; iii) as eq. (30) e (31) resultam no triângulo retângulo destacado na Fig. 9a; iv) por princípio da geometria euclidiana, é possível considerar que as duas histórias paralelas se encontrem em um evento ao infinito, fazendo com que o arco da circunferência de simultaneidade tenda ao segmento de reta $\overline{M N}$; e v) para um corpo extenso rígido, este segmento, a "distância" entre as duas histórias paralelas, possui tamanho $d^{*}$, da mesma 
maneira que no referencial $\mathbb{H}^{*}$. Essa segunda propriedade isométrica vem somar-se à primeira, dada pela eq. (5), e indica que a mudança entre referenciais resulta em uma espécie de rotação do corpo extenso no mapa do espaço-tempo; e isso é imperceptível no limite clássico, dando a entender que o comprimento projetado sobre o eixo $x$ é igual à distância entre a história das duas extremidades.

\section{Problema 4: O "paradoxo" dos gêmeos}

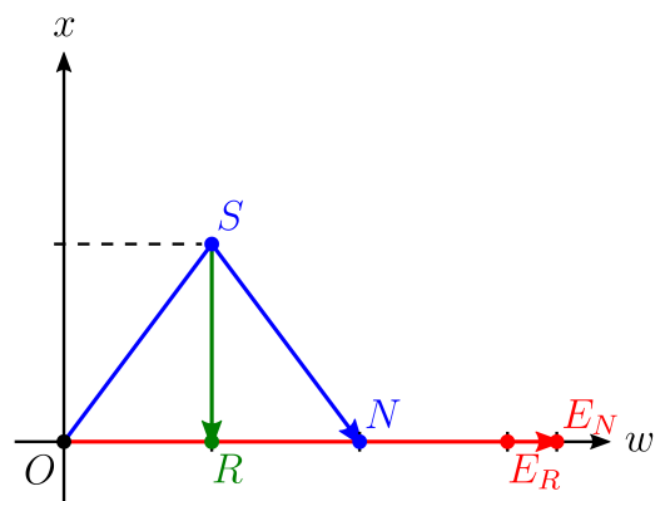

(a) Referencial $\mathbb{H}$.

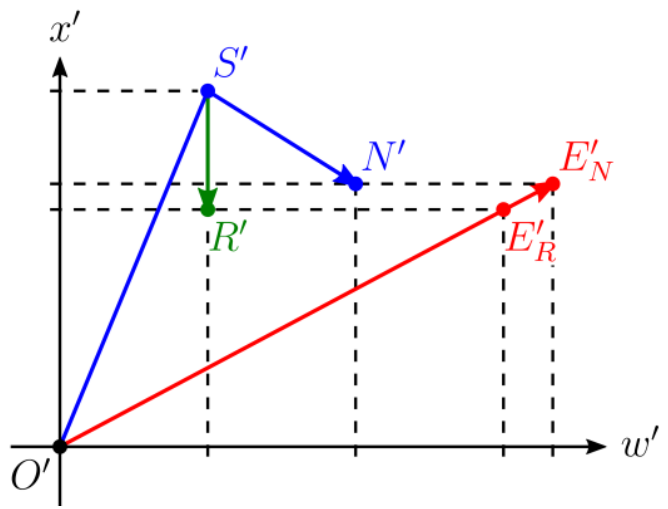

(b) Referencial $\mathbb{H}^{\prime}$.

Fig. 10 - Mapas dos movimentos da nave (em azul), do sinal de rádio (em verde) $e$ da estação (em vermelho).

Ao contrário do método adotado nos três problemas anteriores, em que se estudou, primeiro, o problema físico para, depois, interpretá-lo geometricamente, esta seção usará diretamente o formalismo proposto neste artigo para tratar de um problema notável da relatividade moderna: o paradoxo aparente dos gêmeos. As gêmeas Amanda e Beatriz foram separadas após o término da faculdade, sendo a primeira deixada para trabalhar na estação, que é descrita em repouso no referencial $\mathbb{H}$, e a segunda recrutada para tripular uma nave capaz de viajar a velocidades comparáveis à da luz no vácuo. Na Fig. 10a, $O$ representa a separação das gêmeas nesse referencial e constitui um encontro-padrão, ou seja, um par congruente de eventos. Como visto na seção anterior, dois eventos distintos em histórias diferentes podem estar associados a um mesmo encontro e é conveniente não só tornar, ao menos, um par congruente como também torná-lo o evento-origem. A nave parte do repouso do hangar da estação e muda sua velocidade até atingir o valor constante $v_{n}$. Ao aproximar-se de um sistema estelar com um possível exoplaneta habitável, ela muda novamente sua velocidade para o mesmo valor, mas no sentido oposto, enquanto faz suas análises sobre o astro e as envia via sinal de rádio, evento $S$, para a estação; o que também caracteriza um encontro-padrão entre o sinal e a nave, pois a luz ou qualquer outra onda eletromagnética carrega a informação exata do instante de sua emissão. Os dados enviados por Beatriz 
encontram seu objetivo e são recebidos por Amanda, eventos correspondentes $R$ e $E_{R}$, de tal maneira que a história da estação no período $\overline{O E}_{R}$ tem o mesmo tamanho que a soma entre a história da nave no período $\overline{O S}$ e a história do sinal de rádio no período $\overline{S R}$, uma vez que elas são proporcionais ao tempo medido pelo relógio em repouso no referencial $\mathbb{H}$. Alguns anos depois do recebimento dos dados, a nave finalmente chega à estação e volta ao repouso, eventos correspondentes $N$ e $E_{N}$, permitindo com que as irmãs se reencontrem. A história da estação no período $\overline{O E}_{N}$ tem o mesmo tamanho que a história da nave, que é contínua e suave, começa no evento $O$, passa por $S$ e termina em $N$; e, graças à dilatação temporal, Beatriz envelheceu mais devagar que Amanda. Este resultado é claramente perceptível pelas coordenadas $w$ da Fig. 10a e parece um paradoxo. No entanto, não só a diferença entre as idades das irmãs é real, como também tal resultado é consequência direta do movimento como um todo, pois os relógios biológicos que medem o envelhecimento das gêmeas sofrem independentemente os efeitos da dilação temporal, enquanto a história da nave e de seus tripulantes pode ser aproximada a uma sucessão de MRUs. Na Fig. 10a, os períodos de mudança no movimento da nave são muito pequenos em comparação à história da viagem, tornando-os imperceptíveis, enquanto, no limite clássico, o triângulo $\Delta_{O S N}$ é "achatado", fazendo o par de eventos $N$ e $E_{N}$ tender à congruência, bem como o par $R$ e $E_{R}$. Já em uma mudança de referencial, cada período de seu movimento, constante ou não, sofre a atuação das transformações dadas pelas eq. (12a) e (12b), de tal maneira que:

$$
\begin{aligned}
& \int_{O \prime}^{N^{\prime}} \mathrm{d} s^{\prime}{ }_{n}=\frac{c}{\mathrm{u}} \int_{O}^{N} \mathrm{~d} s_{n}-\frac{\mathrm{v}}{\mathrm{u}} \int_{O}^{N} \mathrm{~d} x_{n}, \\
& \int_{O \prime}^{N^{\prime}} \mathrm{d} x^{\prime}{ }_{n}=\frac{c}{\mathrm{u}} \int_{O}^{N} \mathrm{~d} x_{n}-\frac{\mathrm{v}}{\mathrm{u}} \int_{O}^{N} \mathrm{~d} s_{n} .
\end{aligned}
$$

Da mesma forma, o movimento do sinal de rádio sofre a atuação de transformações análogas às anteriores, resultando na Fig. 10b, que preserva, por isometria, as durações da Fig. 10a. Essas transformações preservam os encontros de tal maneira que o período da estação, $\left(\overline{O E}_{R}\right)^{\prime}$, tem tamanho igual à soma dos tamanhos da história da nave no período $(\overline{O S})^{\prime}$ e da história do sinal de rádio no período $(\overline{S R})^{\prime}$, enquanto que o período $\left(\overline{O E}_{N}\right)^{\prime}$ tem o mesmo tamanho que a história da nave no referencial $\mathbb{H}^{\prime}$, que começa no evento $O^{\prime}$, passa por $S^{\prime}$ e termina em $N^{\prime}$.

\section{Problema 5: O "paradoxo" da contração do espaço}

Nesta seção será estudado, usando diretamente a nova geometria, outro problema notável da relatividade moderna: o paradoxo aparente da contração do espaço. No referencial $\mathbb{H}$, a nave onde viaja Beatriz entra, com velocidade constante, de norma $v_{n}$ comparável à da luz, e paralela ao eixo $x$, em um dos hangares da estação onde está Amanda. A covelocidade da nave tem norma $u_{n}$ e o hangar tem comprimento $d_{h}$, enquanto a estação é descrita em repouso. Por outro lado, o comprimento da nave é $d_{n}^{*}$ quando medida no referencial $\mathbb{H}^{*}$, em 
que, agora, ela é considerada em repouso. Tomando que $d_{n}^{*}$ é maior que $d_{h}$, o comprimento medido para a nave, $d_{n}$, no referencial $\mathbb{H}$ pode ser menor que o comprimento em repouso do hangar graças ao fenômeno da contração do comprimento, pois, se não bastasse a preocupação da relatividade clássica em saber onde os móveis estão em cada referencial, a relatividade moderna trouxe também a dificuldade em saber quando fazer as medidas. Usando o mapa do espaço-tempo proposto neste trabalho, foi demonstrado que o MRU de um corpo extenso é delimitado por duas histórias paralelas, que representam suas extremidades como pontos materiais e que sempre distam entre si o valor do comprimento medido em repouso. Da mesma maneira, a projeção desse valor sobre o eixo $x$ é o comprimento contraído, ou seja, aquele considerado simultâneo. Assim, não é muito difícil perceber que dois corpos extensos em movimento relativo entre si podem ter comprimentos contraídos maiores, menores ou até iguais dependendo do referencial, graças à rotação atribuída à transformação.

Por exemplo, na transformação dos movimentos da nave e da estação descritos de referencial $\mathbb{H}$ para um referencial $\mathbb{H}^{\dagger}$, arbitrário, que tem seu eixo $x^{\dagger}$ se movendo paralelamente ao eixo $x$ com velocidade e covelocidade relativas de norma, respectivamente, $\mathrm{v}$ e u, o comprimento contraído do hangar, $d_{h}^{\dagger}$, e o comprimento contraído da nave, $d_{n}^{\dagger}$, podem relacionar-se usando a composição de covelocidades, a partir da eq. (13a), de tal maneira que:

$$
\begin{aligned}
& d_{h}^{\dagger}=k d_{n}^{\dagger}, \\
& k=\frac{c}{u_{n}}\left(1-\frac{\mathrm{v}}{c} \frac{v_{n}}{c}\right) \frac{d_{h}}{d_{n}^{*}} .
\end{aligned}
$$

A Fig. 11 mostra a situação em que $k=1$, mas este problema também pode ser estudado usando os encontros entre as extremidades dos dois corpos extensos. É conveniente que a análise inicial seja feita tanto no referencial em que a estação é considerada em repouso, quanto no referencial em que a nave é considerada em repouso, pois um encontro mantém a mesma coordenada espacial, enquanto a história de um ponto material em MRU só passa uma vez pela posição onde está o ponto material estático. Nessas condições, no referencial HH, Fig. 12a, o nariz da nave alcança a entrada do hangar no evento $N_{1}$ e a sua saída ocorre no evento $O$, que é considerado o encontro-padrão, e a cauda da nave alcança a entrada do hangar no evento $N_{3}$ e a sua saída acontece no evento $N_{4}$. Já no referencial $\mathbb{H}^{*}$, Fig. $12 \mathrm{~b}$, o nariz da nave alcança a entrada do hangar no evento $E_{1}^{*}$ e a sua saída acontece no evento $O^{*}$; e a cauda da nave alcança a entrada do hangar no evento $E_{3}^{*}$ e a sua saída ocorre no evento $E_{4}^{*}$. Graças à isometria das durações e a isometria da distância entre as histórias paralelas: i) o par $E_{3}^{\dagger}$ e $N_{3}^{\dagger}$ na Fig. 11 corresponde ao encontro entre a cauda da nave e a entrada do hangar e ii) este problema pode ser representado no referencial $\mathbb{H}^{\prime}$ como mostram as Fig. 13a e 13b. 


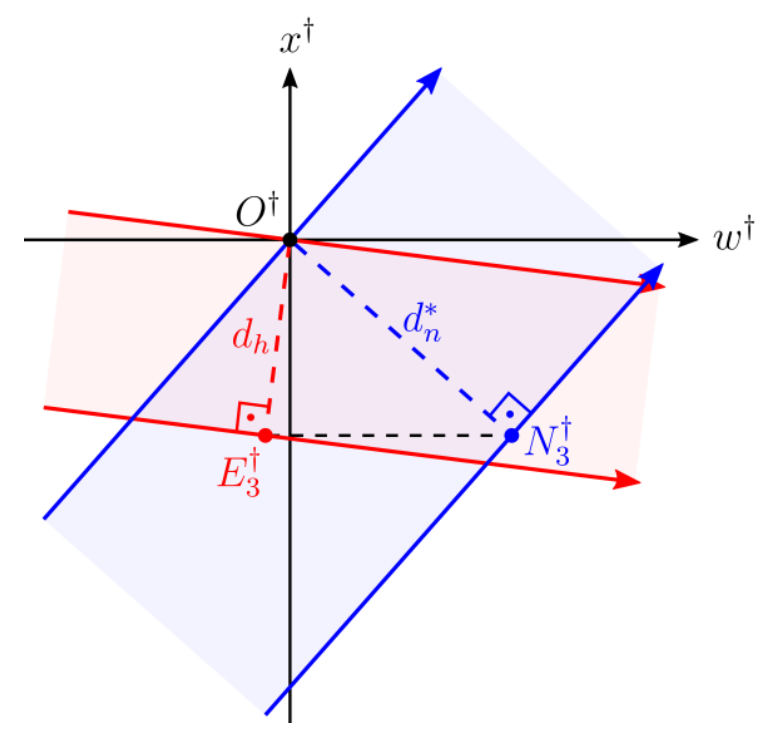

Fig. 11 - Mapa, no referencial $\mathbb{H}^{\dagger}$, dos movimentos da nave (limitada em azul) e do hangar (limitado em vermelho) para a situação em que $k=1$.

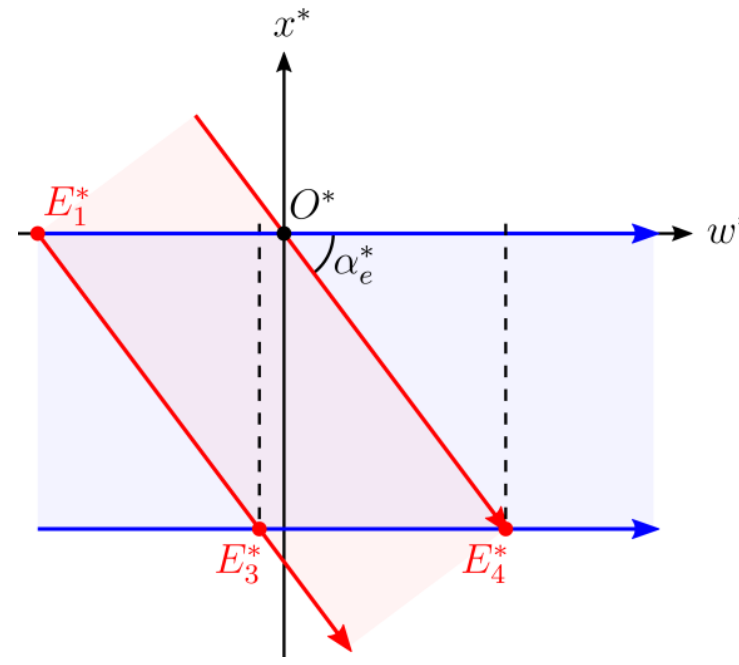

(a)

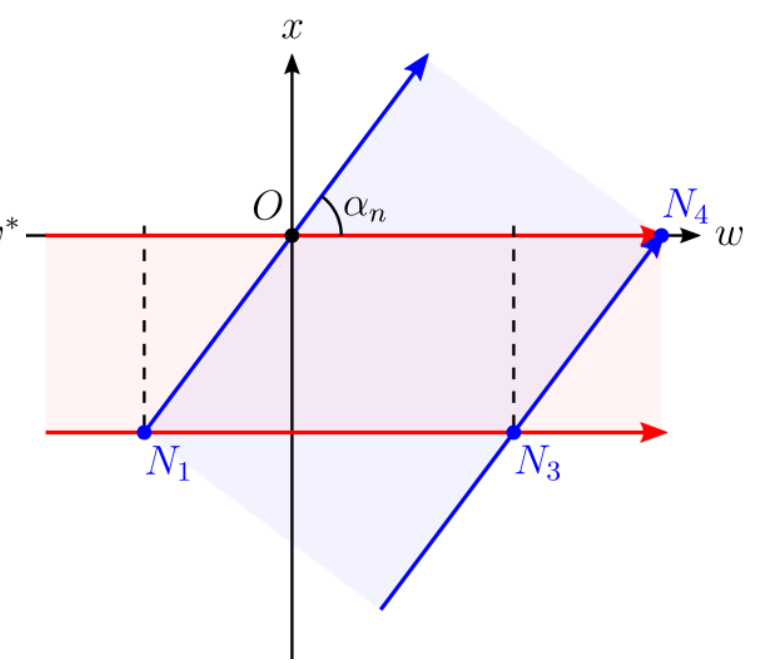

(b)

Fig. 12 - Mapas dos movimentos da nave (limitada em azul) e do hangar (limitado em vermelho).

Em relação às durações, a ordem cronológica dos eventos de encontro pode ser diferente para cada um dos dois relógios comóveis, dependendo do ângulo $\alpha_{n}$, que é congruente ao ângulo $\alpha_{e}^{*}$, e dos comprimentos em repouso da nave, $d_{n}^{*}$, e do hangar, $d_{h}$. Essa diferença na sucessão de eventos pode causar confusão quando se tenta estabelecer uma relação de causalidade entre eles, pois, nas Fig. 12a e 12b, a sequência dos eventos de encontro para o relógio de Beatriz é: $N_{1}, O, N_{3}$ e $N_{4}$, enquanto que, para o relógio de Amanda, a ordem é: $E_{1}, E_{3}, O$ e $E_{4}$, invertendo a saída do nariz da nave pela entrada da cauda. Até 
mesmo se $d_{n}^{*}$ fosse igual a $d_{h}$, as mesmas sequências seriam observadas. Esse resultado estranho e aparentemente contraditório deve-se ao fato de, neste problema, haver dois fenômenos sob análise: i) a passagem da nave por dentro do hangar e ii) a passagem do hangar ao redor da nave, que, contrariando a intuição, são fenômenos distintos. Já em relação às histórias, relacionadas a quaisquer outros relógios, para os referenciais em que $k>1$, a saída do nariz ocorre antes da entrada da cauda, para aqueles em que $k=1$, esses eventos ocorrem simultaneamente, e, para $1<k<0$, a cauda entra antes da saída do nariz.

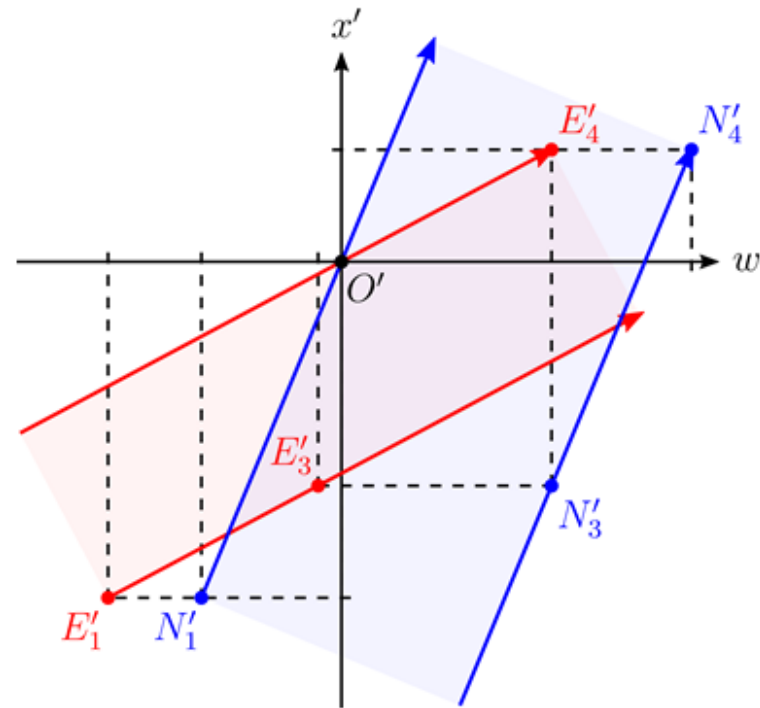

(a)

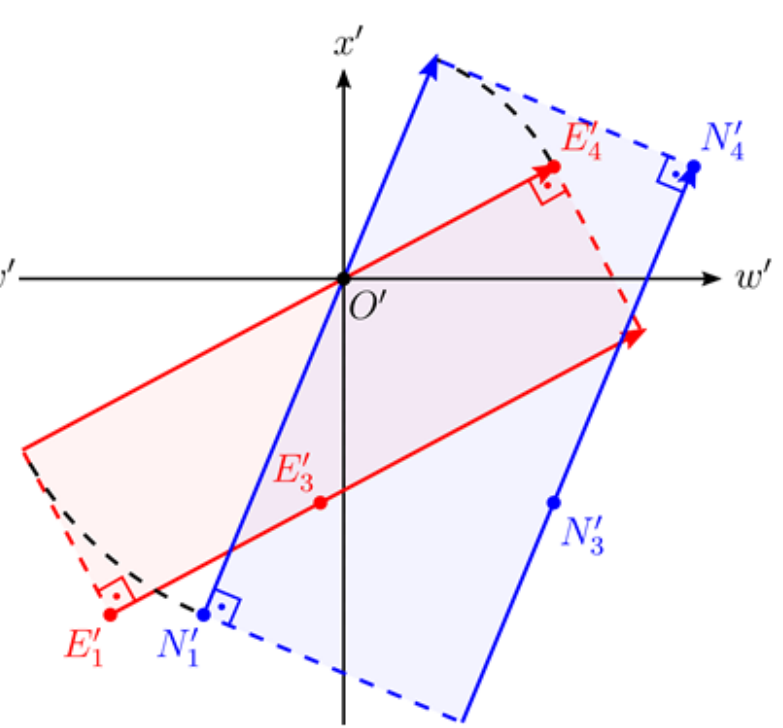

(b)

Fig. 13 - Mapa, no referencial $\mathbb{H}$, dos movimentos da nave (limitada em azul) e do hangar (limitado em vermelho).

Os resultados tanto para as medidas dos comprimentos contraídos da nave e do hangar, quanto para as ordens dos eventos de encontro desses movimentos, são bastante antiintuitivos e parecem paradoxais em termos do resultado observado no cotidiano. Entretanto, ao analisar o problema no limite clássico, em que os ângulos $\alpha_{n}$ e $\alpha_{e}^{*}$ são muito pequenos e os comprimentos da nave e do hangar são considerados dentro da ordem de grandeza usual do dia a dia, a sequência dos eventos, não só são compatíveis com o resultado clássico, como também os pares de eventos correspondentes tendem à congruência, e os comprimentos contraídos tendem ao valor dos comprimentos em repouso. Nesse limite, removendo a constante $c$ do eixo temporal, o resultado é exatamente o tradicional diagrama horário da posição e o paradoxo só surge quando se toma a parte pelo todo, ou seja, considera-se o resultado no limite clássico como um resultado geral. Outrossim, vale a pena frisar que esses são resultados obtidos pela medida, e não se devem a uma simples percepção do observador, ou seja, não se devem ao "aspecto visual" (OSTERMANN; RICCI, 2002, CAVALCANTI; OSTERMANN, 2007) do objeto em movimento relativista. Para o observador, a nave caber ou não no hangar depende muito da escala de grandezas do problema, pois a luz emitida em 
cada um dos encontros demora tempos diferentes para alcançá-lo, causando um efeito particular de perspectiva.

\section{Problema 6: O "paradoxo" do disco rígido girante}

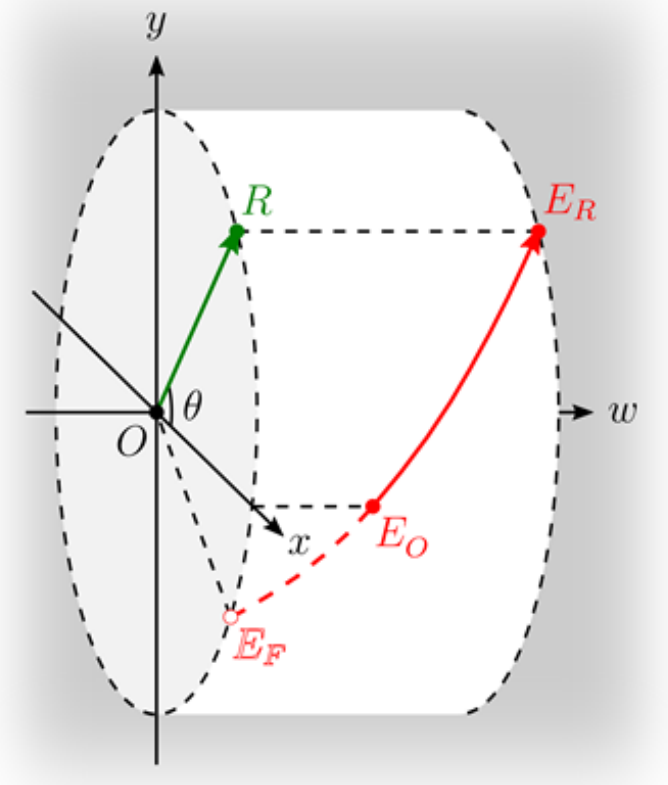

(a)

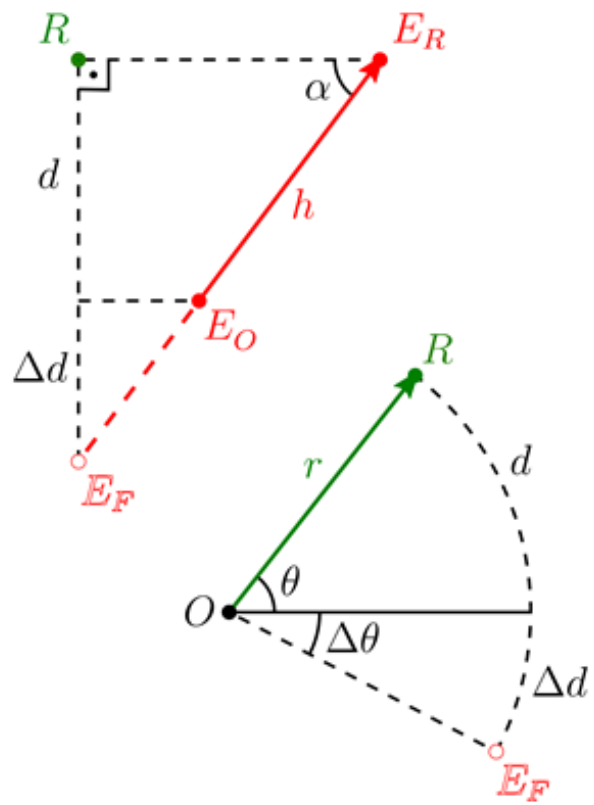

(b)

Fig. 14 - (a) Mapa tridimensional do espaço-tempo, no referencial $\mathbb{H}$, do movimento circular do receptor como um ponto material (em vermelho). (b) Projeções do movimento do receptor sobre a base e a lateral do cilindro mostrado na figura ao lado.

Continuando o método começado nas duas seções anteriores de abordar os problemas usando diretamente a nova geometria, aqui, será feito um estudo sobre mais um problema notável da relatividade moderna: o paradoxo aparente do disco girante. Amanda e Beatriz estão na torre de comando da estação, que possui um relógio fixo e é descrita em repouso no referencial $\mathbb{H}$, e operam um compartimento circular de testes capaz de girar, em suas partes mais periféricas, a velocidades comparáveis à luz. Dentro desse compartimento, há uma fonte laser e um receptor de luz de tal maneira que a primeira está em repouso no centro de rotação e o segundo está girando, com velocidade constante de norma $v_{r}$, junto com o compartimento e a uma distância fixa, $r$, do centro. Um pulso luminoso é emitido pela fonte, evento $O$ na Fig. $14 \mathrm{a}$, e é detectado pelo receptor, evento $R$. Já o evento $E_{R}$ corresponde à detecção do pulso na história do receptor, que é descrito como um ponto material em movimento circular. Nestas condições, i) a Fig. 14a pode ser chamada de mapa tridimensional do espaço-tempo; ii) o 
movimento da luz está contido num plano $x y$, puramente espacial; iii) o movimento do receptor ocorre num cilindro, cuja base é o disco de raio $r$, também pertencente ao plano $x y$; iv) a Fig. 14b mostra as projeções do movimento do receptor sobre a base e a lateral do cilindro; e v) a detecção do pulso até poderia ser tomada como o encontro-padrão, mas essa escolha atrapalharia a clareza na Fig. 14a.

Neste ponto, a discussão sobre o conceito de corpo rígido girante se torna essencial. Não é muito difícil perceber que o valor da velocidade angular, ou seja, a taxa de variação do ângulo de rotação espacial, $\theta$, em relação à história do movimento do receptor, não pode ser considerada constante sem violar o Postulado 1, pois isso geraria um referencial inercial privilegiado. Isto ocorre porque a transformação entre os tempos depende da velocidade, que, não só varia conforme o raio $r$, como também está sujeita à composição de movimentos; o que faz com que períodos considerados iguais em um referencial sejam, via de regra, diferentes em outros. Assim, a maneira ideal de descrever a rotação de um corpo considerado rígido é considerar, como constante, a taxa de variação, $\Omega$, do ângulo $\theta$ em relação à duração de seu movimento de tal maneira que, considerando $W$ referente à duração de uma volta completa:

$$
\Omega=\frac{2 \pi}{W} .
$$

A definição da taxa de variação $\Omega$, que tem seu significado geométrico dado por:

$$
\operatorname{tg}(\alpha)=\Omega r
$$

com $\alpha$ mostrado na Fig. 14b, permite deduzir, a partir das eq. (9a) e (9b), as normas da covelocidade e da velocidade do receptor, respectivamente:

$$
\begin{aligned}
& u_{r}=c\left(1+\Omega^{2} r^{2}\right)^{-\frac{1}{2}}, \\
& v_{r}=\Omega c r\left(1+\Omega^{2} r^{2}\right)^{-\frac{1}{2}},
\end{aligned}
$$

que é um resultado importante para medir o fenômeno da dilatação temporal sobre este ponto. A definição de corpo rígido girante ideal adotada aqui explica bem o funcionamento dos relógios analógicos mostrados nas Fig. $2 \mathrm{a}, 2 \mathrm{~b}, 5$ e 7 , pois mantém a duração de seus movimentos, o que permite construir os mapas bidimensionais subsequentes, como também resolve uma possível situação paradoxal em que, no caso limite para $r$ considerado muito grande, a velocidade do receptor excederia o valor $c$. Mais ainda, essa definição recai no resultado esperado no limite clássico, que mantém constante o valor da velocidade angular, uma vez que a $\operatorname{tg}(\alpha)$ é aproximadamente o sen $(\alpha)$ para um $r$ muito pequeno.

O movimento circular uniforme estabelecido até agora já seria suficiente para encerrar esta seção, mas ainda poderiam pairar dúvidas a respeito do efeito da contração do comprimento, na situação em que o receptor é considerado em repouso sobre o disco da Fig. 14a. Essa discussão extrapola um pouco a definição de referenciais inerciais apresentada neste artigo, pois o receptor não pode ser considerado parado e livre de interações, mas isso não é 
um problema; não, ao menos, neste exemplo, como será demonstrado a seguir. A fonte e o receptor podem ser considerados em repouso em um autoproclamado referencial nãoinercial; e, fazendo analogia com o Problema 4, não só a dilatação temporal só se aplica na direção tangencial à curva, mantendo $r$ inalterado, como também a norma, $c$, da velocidade do pulso luminoso só depende de suas componentes radial e tangencial, com esta última igual a $-v_{r}$. Assim, é razoável concluir que a trajetória/história do pulso nesse referencial nãoinercial é maior que no referencial inercial $\mathbb{H}$, sendo curvada no sentido oposto à rotação do receptor, por composição de movimentos. O fenômeno da dilatação temporal afeta diretamente o tamanho da história, $h$, congruente a $r$, entre os eventos $E_{R}$ e $E_{O}$, simultâneo à emissão do pulso no referencial $\mathbb{H}$, e a distância percorrida pelo receptor, $d$, nesse mesmo período é menor que a componente tangencial da trajetória do pulso no referencial nãoinercial. Esta contração espacial pode ser escrita como:

$$
\frac{c}{u} d=d+\Delta d
$$

em que o incremento na distância, $\Delta d$, é convenientemente colocado na Fig. 14b para permitir a comparação. Considerando que o receptor executa um movimento circular, que o raio $r$ não se altera e que $d=\theta r$ e $\Delta d=r \Delta \theta$, é fácil perceber a relação angular:

$$
\frac{c}{u} \theta=\theta+\Delta \theta
$$

indicando que a contração do comprimento do compartimento não resulta em uma deformação radial, mas em uma precessão angular, $\Delta \theta$, de tal maneira que, no referencial nãoinercial, o evento pertencente à história do receptor, e simultâneo à emissão do pulso, seria análogo ao $E_{F}$.

\section{Considerações finais}

O conteúdo apresentado neste artigo é uma continuação da transposição didática pioneira apresentada em 2013 (ALMEIDA, 2013) e possui o papel relevante de sugerir uma nova linha de discussão sobre o ensino da relatividade moderna no Brasil. Na verdade, essa nova linha parece nova até em contexto internacional; e, talvez, um dos prováveis motivos que a tornam desconhecida no ensino seja sua pouca expressividade na própria pesquisa em Física, pois ela parece ter chegado "tarde": não oferece uma vantagem decisiva para os físicos e parece um retrocesso, um retorno ao "euclidianismo", para os matemáticos. Essa baixa expressividade é percebida i) pela falta de consenso sobre seus termos e conceitos e ii) pela baixa quantidade de bons trabalhos sobre o assunto. É comum que essa abordagem euclidiana seja "redescoberta" de forma independente por diversos autores nestes últimos 50 anos, inclusive por este presente autor, que está em grande débito com van Linden (2018), mas, faltava na literatura um trabalho que atacasse de forma meticulosa os problemas históricos da relatividade. Assim, destrinchar os seis problemas propostos aqui foi um ganho conceitual, tanto para seu ensino, quanto para sua própria compreensão física. É evidente que ainda 
existem muitos outros problemas da relatividade moderna que precisam ser estudados à luz dessa nova geometria antes de uma correta compreensão de suas propriedades e de uma firme analogia conceitual com as abordagens canônicas, mas, aparentemente, não há qualquer fenômeno, de competência da TRE, que ela não possa operar com sucesso e de forma equivalente. Isso, aliado com uma possível vantagem em seu uso educacional, torna-a uma abordagem promissora para o ensino.

\section{Referências bibliográficas}

ALMEIDA, O. F. Proposta de transposição didática para o ensino de relatividade especial: uma abordagem para o Ensino Médio. 2013. 48 f. Trabalho de Conclusão de Curso (Licenciatura em Física) - Instituto de Física, UFRJ, Rio de Janeiro.

CAVALCANTI, C. J. H.; OSTERMANN, F. Deformações geométricas e velocidade superluminal aparentes em objetos em movimento relativístico. Revista Brasileira de Ensino de Física, v. 29, n. 3, p. 355-372, 2007.

EINSTEIN, A. Zur elektrodynamik bewegter körper. Annalen der Physik, v. 322, n. 10, p. 891-921, 1905.

EINSTEIN, A.; LAUB, J. Über die elektromagnetischen grundgleichungen für bewegte körper. Annalen der Physik, v. 331, n. 8, p. 532-540, 1908.

EVENT HORIZON TELESCOPE COLLABORATION. First M87 event horizon telescope results. I. The shadow of the supermassive black hole. The Astrophysical Journal Letters, v. 875 , n. 1, p. 1-17, 2019.

GALISON, P. Einstein's Clocks and Poincare's Maps: Empires of time. Reprint. New York: W. W. Norton \& Company, 2004.

JEGAT, A. Un modèle platonicien (euclidien-projectif) pour la théorie de la relativité restreinte. Archive Ouverte HAL, 2014. Disponível em: $<$ https://hal.archives-ouvertes.fr/hal01081576/document>. Acesso em: 29 set. 2020.

LIGO SCIENTIFIC COLLABORATION; VIRGO COLLABORATION. Observation of gravitational waves from a binary black hole merger. Physical Review Letters, v. 116, n. 6, p. 1-16, 2016.

MINKOWSKI, H. Die grundgleichungen für die elektromagnetischen vorgänge in bewegten körpern. Nachrichten Von Der Gesellschaft Der Wissenschaften Zu Göttingen, 
Mathematisch-Physikalis-Che Klasse. Göttingen, 1908. p. 53-111.

MONTANUS, H. Special relativity in an absolute Euclidean space-time. Physics Essays, v. 4, n. 3, p. 350-356, 1991.

MONTANUS, J. M. C. Proper time physics. Hadronic Journal, v. 22, n. 6, p. 625-673, 1999.

NEWBURGH, R. G.; PHIPPS JR., T. E. A space-proper time formulation of relativistic geometry. Physical Sciences Research Papers, n. 401. Bedford: Air Force Cambridge Research Laboratories, 1969.

NEWBURGH, R. G.; PHIPPS JR, T. E. Relativistic time and the principle of Carathéodory. Il Nuovo Cimento B (1965-1970), v. 67, p. 84-102, 1970.

OSTERMANN, F.; MOREIRA, M. A. Uma revisão bibliográfica sobre a área de pesquisa "física moderna e contemporânea no ensino médio". Investigações em Ensino de Ciências, v. 5, n. 1, p. 23-48, 2000.

OSTERMANN, F.; RICCI, T. F. Relatividade restrita no Ensino Médio: contração de Lorentz-Fitzgerald e aparência visual de objetos relativísticos em livros didáticos de Física. Caderno Brasileiro de Ensino de Física, v. 19, n. 2, p. 176-190, 2002.

POINCARÉ, J. H. Sur la dynamique de l'électron. Rendiconti del Circolo Matematico di Palermo, v. 21, n. 1, p. 129-175, 1906.

MACHOTKA, R. Euclidean Model of Space and Time. Journal of Modern Physics, v. 9, n. 6, p. 1215-1249, 2018.

REZENDE, F.; BARROS, S. L. S. Teoria aristotélica, teoria do impetus ou teoria nenhuma: um panorama das dificuldades conceituais de estudantes de física em mecânica básica. Revista Brasileira de Pesquisa em Educação em Ciências, v. 1, n. 1, p. 43-56, 2001.

RODRIGUES, C. M.; SAUERWEIN, I. P. S.; SAUERWEIN, R. A. Uma proposta de inserção da teoria da relatividade restrita no Ensino Médio via estudo do GPS. Revista Brasileira de Ensino de Física, v. 36, n. 1, p. 1-7, 2014.

SALINAS, S. R. A. Apresentação: Cem anos da observação do eclipse solar de Sobral. Revista Brasileira de Ensino de Física, v. 41, supl. 1, e20190272, 2019. 
SAMPAIO, W. S.; OLIVEIRA, A. N.; SIQUEIRA, M. C. A. As teorias da relatividade no ensino básico: uma revisão de literatura para traçar o perfil dos trabalhos publicados no Brasil entre 2000 e 2018. Conexões Ciência e Tecnologia, v. 13, n. 4, p. 45-53, 2019.

TERRAZZAN, E. A. A inserção da física moderna e contemporânea no ensino de física na escola de $2^{\circ}$ grau. Caderno Catarinense de Ensino de Física, v. 9, n. 3, p. 209-214, 1992.

VAN LINDEN, R. F. J. Euclidean Relativity. 2018. Disponível em: $<$ https://www.euclideanrelativity.com/>. Acesso em: 29 set. 2020. 